\title{
Influence of carbon nanotube and ionic liquid on properties of natural rubber nanocomposites
}

\author{
A. Krainoi ${ }^{1}$, C. Kummerlöwe ${ }^{2}$, Y. Nakaramontri $^{1}$, S. Wisunthorn ${ }^{1}$, N. Vennemann ${ }^{2}$, S. Pichaiyut ${ }^{1}$, \\ S. Kiatkamjornwong ${ }^{3,4}$, C. Nakason ${ }^{1 *}$ \\ ${ }^{1}$ Faculty of Science and Industrial Technology, Prince of Songkla University, Surat Thani Campus, 84000 Surat Thani, \\ Thailand \\ ${ }^{2}$ Faculty of Engineering and Computer Science, University of Applied Sciences Osnabrück, 49076 Osnabrück, Germany \\ ${ }^{3}$ Chulalongkorn University, Phayathai Road, Pathumwan, 10330 Bangkok, Thailand \\ ${ }^{4}$ FRS(T), Academy of Science, the Office of Royal Society, Sanam Suea Pa, Dusit, 10300 Bangkok, Thailand
}

Received 16 September 2018; accepted in revised form 17 November 2018

\begin{abstract}
Some properties of carbon nanotube (CNT) filled natural rubber (NR) composites were improved by adding an ionic liquid (IL), 1-butyl-3-methyl imidazolium bis (trifluoromethylsulphonyl)mide (BMI). In this work, the CNT and IL (CNT-IL) were mixed with NR by latex mixing method. Cure characteristics, thermo-mechanical properties, Payne effect, electrical conductivity and thermal stability were investigated. It was found that IL (BMI) accelerated vulcanization reactions and reduced scorch time. In addition, Fourier Transform Infrared (FTIR) results confirmed the role of IL in NR composites along with the reaction between CNT and NR molecules. The temperature scanning stress relaxation (TSSR) measurement was used to assess thermo-mechanical properties, and a relaxation peak of IL was found due to interactions of cations and anions in IL (BMI). Furthermore, the Payne effect was used to qualitatively analyze the roles of IL and CNT in three-dimensional CNT networks in the NR matrix. It was found that CNT dispersion was finer in the NR/CNT composites with IL. Furthermore, the NR/CNT-IL composite had higher electrical conductivity and lower percolation threshold concentration than the NR/CNT composite.
\end{abstract}

Keywords: nanocomposites, natural rubber, carbon nanotubes, Ionic liquid, 1-butyl-3-methyl imidazolium bis(trifluoromethylsulphonyl)imide (BMI)

\section{Introduction}

Natural rubber (NR) composites with carbon nanotube (CNT) filler have been widely investigated with the main purpose to prepare strong elastic materials with high electrical conductivity. Typically, the addition of CNT could transform NR from electric insulator to conductive material with outstanding flexibility, elasticity and mechanical properties [1-3]. However, the optimum electrical conductivity and other related properties of NR/CNT composites are mainly controlled by localization and three dimensional networks of CNTs in the rubber matrix $[4,5]$.
That is, the random orientation of CNT can give twodimensional (2D) and three-dimensional (3D) CNT networks [6]. Normally, three-dimensional CNT networks are formed before reaching the percolation threshold concentration (PTC) of the incorporated filler, creating conductive pathways for electron transfer. Nevertheless, agglomeration of CNT is typical due to interactions of polar functional groups on CNT surfaces via hydrogen bonds and Van-der Waals attraction $[7,8]$. This may cause inferior electrical conductivity and mechanical properties of the NR/ CNT composites $[9,10]$. 
To enhance electrical conductivity of the rubber composites, several methodologies have been exploited to improve the CNT dispersion in rubber matrix. One prominent approach is use of CNT mixed with an ionic liquid (IL) [2]. It is noted that IL is typically an organic salt with low melting point (typically $<100^{\circ} \mathrm{C}$ ), low vapor pressure, and high thermal stability [2]. Typically, the IL molecules consist of a cation and an anion that connect to hydrophobic alkyl groups [11]. In addition, the IL molecules have hydrophilic and hydrophobic parts of the inorganic and organic salts in their molecules. It is noted that the hydrophobic part is capable of interacting with CNT surfaces through cation- $\pi$ interaction [12]. Also, some ionic liquids contain $-\mathrm{C}=\mathrm{C}-$ in the alkyl chain, and this could interact with diene rubbers via sulfur bridges from sulfur vulcanization [13]. Therefore, IL could bridge CNT surfaces with the rubber matrix [13].

The imidazolium ionic liquid has been widely used in various types of polymer matrix [7, 9, 14-16]. It was found that the imidazolium groups play an important role in improving the ionic conductivity of acrylonitrile butadiene rubber (NBR) [14]. Furthermore, $\mathrm{NBR} / \mathrm{SiO}_{2}$ in combination with imidazolium ionic liquid gave good elastomeric properties, high tensile strength, and high electrical conductivity [15]. Also, reduced glass transition temperature $\left(T_{\mathrm{g}}\right)$ was observed due to the plasticizing effect of IL [15]. In addition, carboxylated nitrile butadiene rubber (XNBR) filled with a layered double hydroxide (MgAl-LDH) in combination with imidazolium ionic liquids improved electrical conductivity and thermal stability [16]. Furthermore, MWCNT has been modified with 1-butyl 3-methyl imidazolium bis(trifluoromethylsulphonyl)imide (BMI) and mixed with styrene butadiene rubber solution (SSBR) [7] and with poly(chloroprene rubber) solution (CR) [17]. The distribution of MWCNT agglomerates and individual tubes was good, with formation of MWCNT conducting networks in SSBR matrix giving electrical conductivity up to $0.01 \mathrm{~S} / \mathrm{cm}$. Furthermore, the CR/MWCNT-BMI composites showed improved MWCNT dispersion and related effects [17].

To obtain composites with good CNT distribution and dispersion as well as superior mechanical and electrical properties, preparation technique is practically important. Latex mixing is typically performed by dispersing the MWCNT in water before adding the suspension into natural rubber latex [17]. It was found that a small amount of MWCNT remarkably improved mechanical, thermal, electrical and barrier properties of NR. Furthermore, segregated CNT networks were found, which gave a low electrical percolation threshold concentration at about $0.043 \mathrm{vol} \%$. A comparison of latex and melt mixing methods was also performed in preparing NR/CNT composites [18]. It was found that the NR composite prepared by latex mixing showed superior tensile properties and electrical conductivity over that prepared by melt mixing. The possible technical potential applications of the investigated material should be an electroactive elastomer (EPA) for strain or pressure sensors, stretchable conductors and actuators together with conductive flexible seals and gaskets.

In the present work, improvement of the CNT dispersion and distribution with high quality CNT networks in NR matrix was pursued. For maximal electrical conductivity an IL was also used, namely 1-butyl 3-methyl imidazolium bis(trifluoromethylsulphonyl)imide (BMI). Therefore, CNT-IL (BMI) was first prepared, and then used to fill NR via latex mixing. In addition, cure characteristics, electrical properties, relaxation behavior and thermal resistance were investigated.

\section{Experimental section}

\subsection{Materials}

High ammonia natural rubber latex used as the rubber matrix was manufactured by Von Bundit Co.,Ltd (Surat Thani, Thailand). The reinforcing filler used was multi-wall carbon nanotubes (MWCNT), NC7000 with $9.5 \mathrm{~nm}$ diameter, $1.5 \mu \mathrm{m}$ length, and $90 \%$ purity, manufactured by Nanocyl S.A. (Sambreville, Belgium). The ionic liquid (IL), 1-butyl-3-methyl imidazolium bis(trifluoromethylsulphonyl)imide (BMI), was manufactured by Ionic Liquids Technologies (Heilbronn, Germany). Other chemicals used in the rubber formulation were zinc oxide $(\mathrm{ZnO})$, stearic acid, 2,2'-dithiobis(benzothiazole) (MBTs) and sulfur, as summarized in Table 1.

\subsection{Preparation of CNT, CNT-IL and IL filled-NR composites}

NR/CNT, NR/CNT-IL and NR/IL composites were prepared by latex mixing using sodium dodecyl sulphate (SDS) surfactant $(0.5 \mathrm{wt} \%)$ to stabilize the latex mixture. The CNT or IL or CNT-IL (1:1 by weight) was first mixed in deionized water. The mixture was then conditioned with sonication for about $20 \mathrm{~min}$, and the $\mathrm{pH}$ of latex was then adjusted to 
Table 1. Chemicals and compounding formulations of CNT and CNT-IL hybrid filled NR compounds.

\begin{tabular}{|l|l|c|}
\hline \multicolumn{1}{|c|}{ Chemicals } & \multicolumn{1}{|c|}{ Suppliers } & $\begin{array}{c}\text { Contents } \\
\text { [phr] }\end{array}$ \\
\hline NR latex & Von Bundit Co.,Ltd. (Surat Thani, Thailand)Thani, Thailand & 100 \\
\hline Stearic acid & Imperial Chemical Co. Ltd., Pathum Thani, Thailand & 1 \\
\hline Zinc oxide (ZnO) & Global Chemical Co. Ltd., Samut Prakarn, Thailand & 5 \\
\hline 2,2'-Dithiobis-(benzothiazole) (MBTs) & Flexsys Inc., Termoli, Italy & 1 \\
\hline Sulfur & Ajax Chemical Co. Ltd., Samut Prakarn, Thailand & 2.5 \\
\hline BMI & Ionic Liquids Technologies., Germany & Varied 0-7 \\
\hline CNT & Nanocyl S.A., Belgium & Varied 0-7 \\
\hline
\end{tabular}

about 11 by adding $3 \mathrm{wt} \%$ sodium hydroxide solution. Then, the natural rubber latex $(10 \%$ DRC) was incorporated into the mixture and thoroughly mixed for about $10 \mathrm{~min}$ by a mechanical stirrer. The latex mixture was eventually cast on the smooth surface of a glass plate and then dried in a hot air oven at $60^{\circ} \mathrm{C}$ for $24 \mathrm{~h}$. The dried film was collected and then compounded with the activator, accelerator and vulcanizing agents in an internal mixer $\left(\right.$ Brabender $^{\circledR}$ GmbH \& Co. KG, Duisburg, Germany), with formulation shown in Table 1. In addition, cure characteristics of the rubber compounds were investigated by a moving die rheometer (MDR 2000) (Alpha Technologies, Ohio, USA) at $160^{\circ} \mathrm{C}$. Vulcanized samples were prepared by compression molding at $160^{\circ} \mathrm{C}$ for the respective cure time of each sample.

\subsection{Attenuated total reflection Fourier transform infrared spectroscopy (ATR-FTIR)}

The ATR-FTIR was used to analyze the chemical interactions of NR, CNT and IL. Thus, the gum NR vulcanizate, together with NR/CNT, NR/IL, NR/CNT-IL composite films without other chemicals (i.e., activator, accelerator and curing agent) were prepared. The FTIR analysis was performed by Thermo Nicolet Avatar 360 FTIR (Thermo Electron Corporation, Thermo Nicolet, Madison, WI, USA) over the wide wavenumber range $4000-500 \mathrm{~cm}^{-1}$ with a resolution of $2 \mathrm{~cm}^{-1}$ and 64 scans for recorded spectrum.

\subsection{Cure characteristics}

Cure characteristics of the gum NR vulcanizate together with the CNT, IL and CNT-IL filled NR compounds were determined by using a moving die rheometer (MDR 2000) (Alpha Technologies, Ohio, USA). The measurements were performed at $160^{\circ} \mathrm{C}$ with the fixed oscillation frequency of $1.66 \mathrm{~Hz}$ and $1^{\circ}$ arc amplitude.

\subsection{Vulcanization kinetics}

The activation energy of vulcanization for the gum NR as well as CNT, IL and CNT-IL filled NR compounds was investigated by differential scanning calorimetry (DSC) (Mettler-Toledo Ltd., Gießen, Germany). The analysis was performed over the temperature range $10-300^{\circ} \mathrm{C}$ with four heating rates: 2,10 , 20 and $30^{\circ} \mathrm{C} / \mathrm{min}$.

\subsection{Payne effect}

The Payne effect was determined by measuring the storage modulus with various strain amplitudes for the rubber composites, by using a rubber process analyzer (RPA) (Alpha Technologies, Ohio, USA). The storage shear moduli $\left(G_{0}\right)$ of cured filled NR compounds at different shear strain rates were determined with strain sweep tests for strains spanning $0.56-100 \%$ at the fixed $1 \mathrm{~Hz}$ oscillation frequency and $100^{\circ} \mathrm{C}$.

\subsection{Temperature scanning stress relaxation (TSSR)}

Stress relaxation of the gum NR vulcanizate together with CNT, IL and CNT-IL filled NR composites was investigated by temperature scanning stress relaxation (TSSR) meter (Brabender, Duisburg, Germany). The dumbbell-shaped specimens were first prepared according to ISO 527, type 5A. The samples were first annealed at $100^{\circ} \mathrm{C}$ for $30 \mathrm{~min}$, and then cooled down to room temperature for $30 \mathrm{~min}$ before testing, in order to avoid the storage hardening phenomenon of NR [19]. The test was then started by extending the sample to $50 \%$ strain held at $23{ }^{\circ} \mathrm{C}$ for $2 \mathrm{~h}$. Then, the non-isothermal test was performed by raising the temperature from 23 to $220^{\circ} \mathrm{C}$ with the constant $2{ }^{\circ} \mathrm{C} /$ min heating rate.

\subsection{Thermal analysis}

Thermal stability of NR vulcanizates together with CNT, IL and CNT-IL filled NR composites was 
investigated by thermogravimetric analysis using TGA-SDTA 851 (Mettler Toledo, Zurich, Switzerland). The measurement was performed under nitrogen atmosphere in the temperature range $30-600^{\circ} \mathrm{C}$ before switching to oxygen atmosphere and continuously heating to $900^{\circ} \mathrm{C}$ at the same $10^{\circ} \mathrm{C} / \mathrm{min}$ heating rate. Dynamic mechanical thermal analysis (DMTA) was also carried out by using Dynamic Mechanical Thermal Analyzer (DMTA-V, Rheometric Scientific, New Jersey, USA) in tension mode. The samples were scanned over the temperature range from -100 to $25^{\circ} \mathrm{C}$ with a heating rate of $3{ }^{\circ} \mathrm{C} / \mathrm{min}$, at the fixed mechanical frequency of $10 \mathrm{~Hz}$.

\subsection{Electrical properties}

Electrical properties in terms of electrical conductivity $(\sigma)$ of the gum NR vulcanizate as well as CNT, IL and CNT-IL filled NR composites were measured at room temperature by an LCR meter (Hioki IM 3533, Hioki E.E., Corporation, Nagano, Japan). The meter was connected to plate electrodes of a dielectric test fixture (16451B dielectric test fixture, Test Equipment Solutions Ltd., Berkshire, UK) with $5 \mathrm{~mm}$ electrode diameter. An approximately $2 \mathrm{~mm}$ thick sample was first placed between the plates and then the test was performed over the frequency range $1-10^{5} \mathrm{~Hz}$. The electrical conductivity $(\sigma)$ was then calculated as Equation (1) [20, 21]:

$\sigma=\frac{1}{\rho}=\frac{d}{R_{\mathrm{p}} \cdot A}$

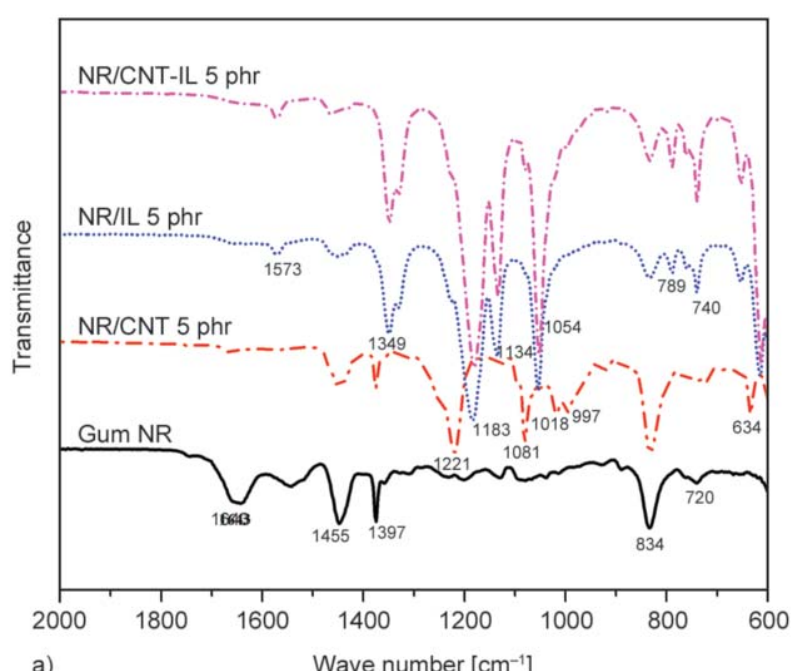

where $d$ and $A$ refer to sample thickness and area of an electrode, respectively. The factor $\rho$ is the volume resistivity, which is the reciprocal of conductivity.

\subsection{Morphological properties}

Morphological properties of NR composites were investigated by scanning electron microscopy (SEM), FEI-Quanta 400, FEI, (Brno, Czech Republic). Each specimen was first cryogenically fractured in liquid nitrogen to create a freshly fractured cross-sectional surface. Then, the samples were sputter-coated with a thin layer of gold under vacuum before characterizing by SEM.

\subsection{Mechanical properties}

Mechanical properties of the NR vulcanizates together with CNT, IL and CNT-IL filled NR composites were investigated using a universal tensile testing machine (Tinius Olsen, Co., Ltd., Honey Crock Lane, UK). The tests were carried out with $500 \mathrm{~mm} / \mathrm{min}^{-1}$ cross-head speed at room temperature, according to ISO 37.

\section{Results and discussion}

\subsection{Attenuated total reflection Fourier transform infrared spectroscopy (ATR-FTIR)}

Figure 1 shows FTIR spectra of the gum NR vulcanizate, together with NR/CNT, NR/IL and NR/CNTIL composites. Also, the potential FTIR peak assignments are listed in Table 2. It is seen that the

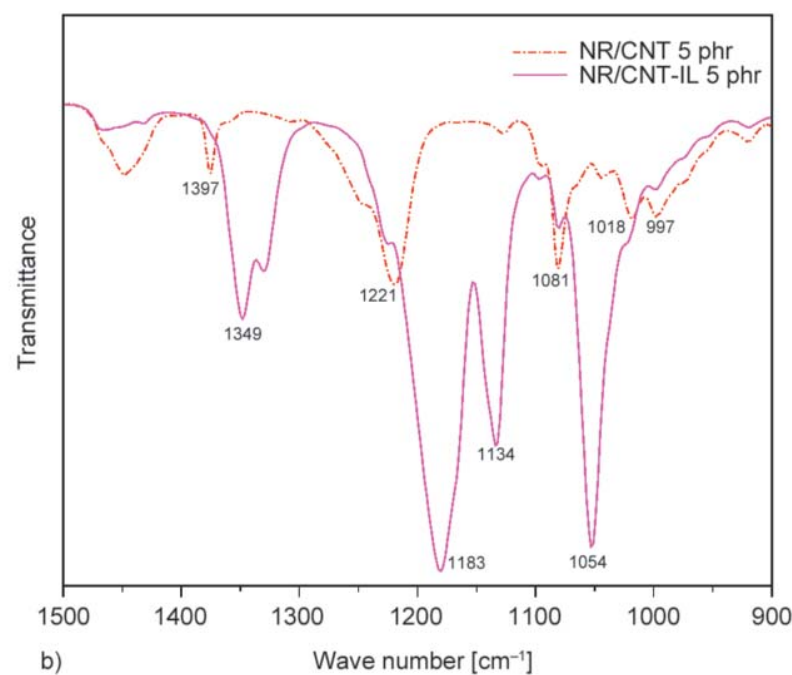

Figure 1. FTIR spectra of the gum NR compound together with NR/CNT, NR/IL and NR/CNT-IL composites (a), and the magnified FTIR spectra of NR/CNT and NR/CNT/IL composites in the wavenumber range from 900 to $1500 \mathrm{~cm}^{-1}(\mathrm{~b})$. 
Table 2. Peak assignments in FTIR spectra for the gum NR, CNT, IL and CNT-IL filled NR vulcanizates.

\begin{tabular}{|c|l|}
\hline $\begin{array}{c}\text { Wave number } \\
{\left[\mathbf{c m}^{-1}\right]}\end{array}$ & \multicolumn{1}{|c|}{ Assignment } \\
\hline 1643 & $\mathrm{C}=\mathrm{C}$ stretching vibration \\
\hline 1573 & $\mathrm{C}-\mathrm{N}$ stretching vibration \\
\hline 1455 & $\mathrm{C}-\mathrm{H}_{\text {scissoring vibration }}$ \\
\hline 1397 & $-\mathrm{CH}_{3}$ bending vibration \\
\hline 1349 & $\mathrm{C}-\mathrm{N}$ stretching vibration \\
\hline 1221 & $\mathrm{C}-\mathrm{O}$ stretching vibration \\
\hline 1183 & $\mathrm{C}-\mathrm{N}$ stretching vibration \\
\hline 1134 & $\mathrm{SO}$ symmetric stretching \\
\hline 1081 & $\mathrm{C}-\mathrm{O}$ stretching vibration \\
\hline 1054 & $\mathrm{~S}-\mathrm{N}-\mathrm{S}$ stretching vibration \\
\hline 1018 & $\mathrm{C}-\mathrm{O}$ stretching vibration \\
\hline 997 & $\mathrm{C}-\mathrm{H}$ out-of-plane bend \\
\hline 834 & $=\mathrm{C}-\mathrm{H}$ out of plane bending \\
\hline 789 & $\mathrm{C}-\mathrm{C}$ vibrations \\
\hline 740 & $\mathrm{CF}{ }_{3}$ symmetric bending \\
\hline 720 & $\left(\mathrm{CH}{ }_{2}\right)$ rocking \\
\hline 662 & $\mathrm{C}-\mathrm{S}$ stretching vibration \\
\hline 634 & $\mathrm{C}-\mathrm{H}$ bending vibration \\
\hline 615 & $\mathrm{C}-\mathrm{H}$ bending vibration \\
\hline & \\
\hline & \\
\hline & \\
\hline 62 &
\end{tabular}

absorption peak at wavenumber $1643 \mathrm{~cm}^{-1}$, which is assigned to $\mathrm{C}=\mathrm{C}$ stretching vibrations of NR molecules, was observed [22]. In addition, the absorption peak at $834 \mathrm{~cm}^{-1}$, which indicates $=\mathrm{C}-\mathrm{H}$ out-ofplane bending, was also observed. Furthermore, absorption peaks at wavenumbers 1455 and $1397 \mathrm{~cm}^{-1}$ were seen, which indicate $\mathrm{C}-\mathrm{H}$ scissoring and $-\mathrm{CH}_{3}$ bending vibrations in NR, respectively. In Figure 1, it is clear that addition of CNT in NR gave new FTIR peaks at wavenumbers 1221,1081 and $1018 \mathrm{~cm}^{-1}$, which are assigned to $\mathrm{C}-\mathrm{O}$ stretching vibrations [23]. Moreover, the peaks of $\mathrm{C}=\mathrm{C}$ stretching vibrations in NR at wavenumber $1643 \mathrm{~cm}^{-1}$ completely disappeared upon adding CNT. This might be due to the chemical interactions of CNT and NR, with a proposed reaction shown in Figure 2 (Reaction A). That is, on mixing NR latex and CNT dispersion, CNT was transformed to [CNT- $\mathrm{Na}^{+}$after addition of $\mathrm{NaOH}$ solution for adjusting the $\mathrm{pH}$ to about 11 [24]. Also, some NR molecular chains might be degraded by thermo-oxidation during drying, which generated ketone groups at NR chain ends $[25,26]$. Therefore, the $\left[\mathrm{CNT}^{-}\right] \mathrm{Na}^{+}$can possibly react with NR at the ketone groups to form NR-CNT linkages. Furthermore, high thermal conductivity and thermal diffusion of CNT in the NR matrix might activate the degradation of NR molecules. This might reduce absorption by $\mathrm{C}=\mathrm{C}$ at $1643 \mathrm{~cm}^{-1}$ in the $\mathrm{NR} / \mathrm{CNT}$ composite, relative to the gum NR vulcanizate. In Figure 1, it is also seen that the FTIR spectrum of NR/IL showed an absorption peak at wavenumber $1573 \mathrm{~cm}^{-1}$, which is assigned to $\mathrm{C}-\mathrm{N}$ stretching vibrations in imidazolium rings [2]. In addition, $\mathrm{SO}_{2}$ symmetric stretching and $\mathrm{CF}_{3}$ symmetric bending vibrations in BMI were also observed in the infrared spectrum of NR/IL vulcanizate, at wavenumbers 1134 and $740 \mathrm{~cm}^{-1}$, respectively [2, 27]. Furthermore, S-N-S stretching and $\mathrm{C}-\mathrm{S}$ stretching vibrations were also observed at 1054 and $662 \mathrm{~cm}^{-1}$, respectively [28]. These peaks indicate various infrared active groups in BMI or the anions of BMI. In addition, the absorption peaks at 789 and $615 \mathrm{~cm}^{-1}$ represent the $\mathrm{C}-\mathrm{C}$ and $\mathrm{C}-\mathrm{H}$ in alkyl chain and in imidazolium ring, respectively. In Figure 1, it is also seen that the FTIR spectrum of NR/CNT-IL composite shows the same peak locations as seen in the infrared spectrum of NR/IL vulcanizate. This might be due to the fact that the CNT did not have strong chemical interactions with IL. However, weak physical interactions of dipole-dipole and $\pi$ - $\pi$ types might occur between CNT and BMI [2], as proposed in Figure 2 (Reaction B). It is clear that the $\mathrm{sp}^{2}$ carbon in CNT might react with the alkoxide ions and cation in imidazoduim rings of BMI. This is confirmed by the infrared spectra in Figure $1 \mathrm{~b}$ showing shifted absorption peaks at wavenumbers 1221, 1081 and $1018 \mathrm{~cm}^{-1}$ in NR/CNT to 1183 and $1054 \mathrm{~cm}^{-1}$ in NR/CNT-IL composite [2, 29], respectively. Thus, it can be anticipated that CNT might bridge NR and BMI by $\pi-\pi$ interactions of CNT and BMI in the NR/CNT-IL composites (Figure 2, Reaction B).

\subsection{Curing characteristics}

Figure 3 shows the curing curves of gum NR compound together with CNT, IL and CNT-IL filled NR compounds. Also, Table 3 shows scorch time $\left(t_{\mathrm{s} 2}\right)$, cure time $\left(t_{\mathrm{c} 90}\right)$, minimum torque $\left(M_{\mathrm{L}}\right)$, maximum torque $\left(M_{\mathrm{H}}\right)$ and torque difference $\left(M_{\mathrm{H}}-M_{\mathrm{L}}\right)$ for various types of NR compounds. Reversion with decreasing torque after the optimum cure level was found in all compounds studied. Furthermore, the reversion phenomenon was more pronounced after the addition of CNT, IL and CNT/IL. This might be due to more breakdown of sulfidic linkages in the presence of CNT, IL and CNT-IL, and also the breakdown of chemical interactions of rubber with the polar functional groups on filler surfaces. Moreover, 


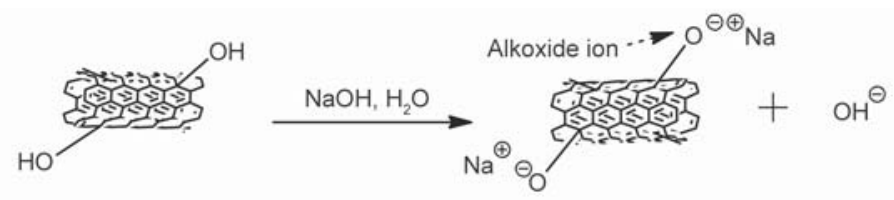

[CNT-]Na+ salts
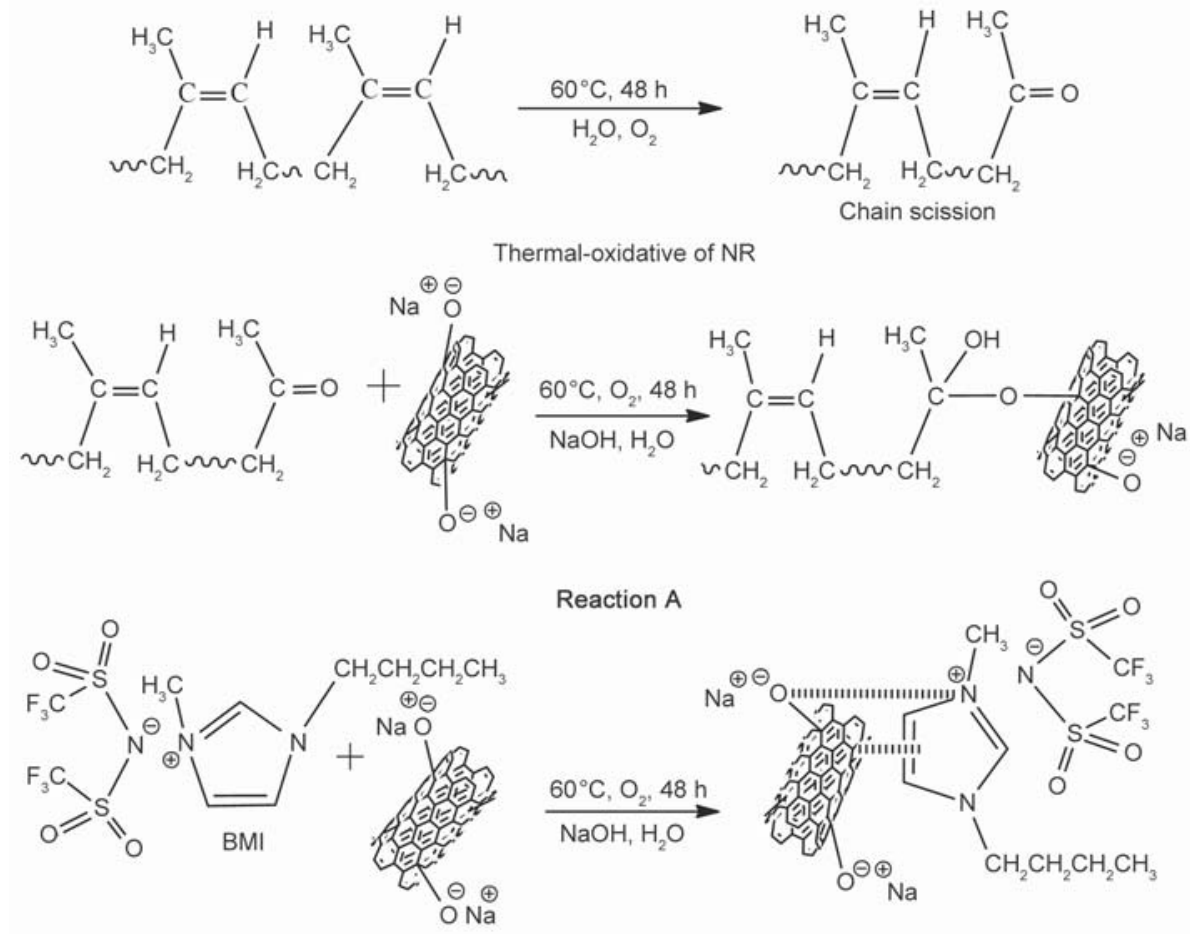

Reaction A

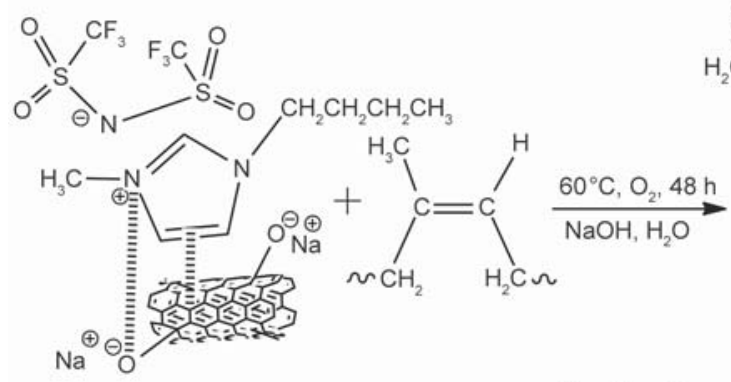

Reaction B
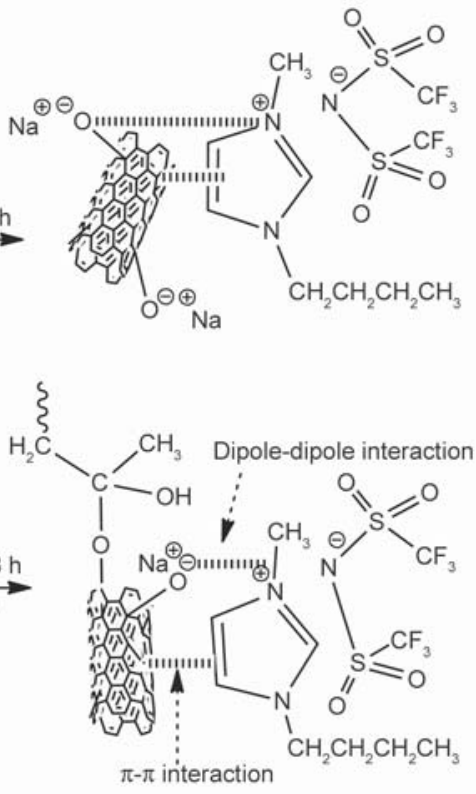

Figure 2. Proposed reaction mechanisms of NR and CNT (Reaction A) as well as NR, CNT and IL (BMI) (Reaction B).

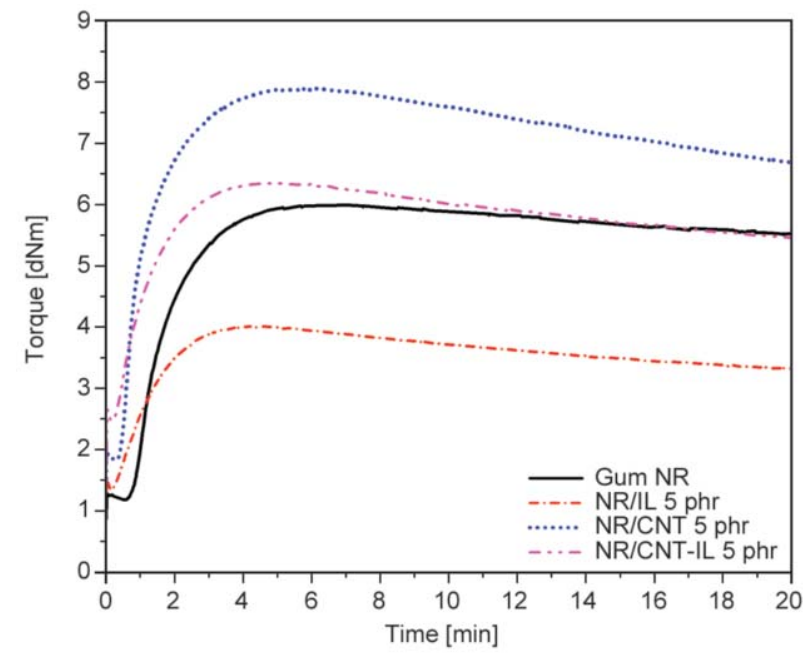

Figure 3. Cure curves of gum NR compound together with NR/CNT, NR/IL and NR/CNT-IL composites. the CNT might activate thermal oxidation and/or degradation of NR and the sulfur linkages because CNT has high thermal conductivity [30]. In Table 3, it is also seen that the scorch time $\left(t_{\mathrm{s} 2}\right)$ of gum NR compound was shortened by addition of CNT due to its high thermal conduction and diffusion in the NR

Table 3. Cure properties of the gum NR compound together with NR/CNT, NR/IL and NR/CNT-IL composites.

\begin{tabular}{|l|c|c|c|c|c|}
\hline \multicolumn{1}{|c|}{ Sample } & $\begin{array}{c}\boldsymbol{M}_{\mathbf{L}} \\
{[\mathbf{d N m}]}\end{array}$ & $\begin{array}{c}\boldsymbol{M}_{\mathbf{H}} \\
{[\mathbf{d N m}]}\end{array}$ & $\begin{array}{c}\boldsymbol{M}_{\mathbf{H}}-\boldsymbol{M}_{\mathbf{L}} \\
{[\mathbf{d N m}]}\end{array}$ & $\begin{array}{c}\boldsymbol{t}_{\mathbf{s 2}} \\
{[\mathbf{m i n}]}\end{array}$ & $\begin{array}{c}\boldsymbol{t}_{\mathbf{c 9 0}} \\
{[\mathbf{m i n}]}\end{array}$ \\
\hline Gum NR & 1.18 & 5.99 & 4.81 & 1.33 & 3.32 \\
\hline NR/CNT 5 phr & 1.83 & 7.90 & 6.07 & 0.71 & 2.79 \\
\hline NR/IL 5 phr & 1.34 & 4.01 & 2.67 & 1.77 & 2.56 \\
\hline NR/CNT-IL 5 phr & 2.45 & 6.35 & 3.90 & 1.05 & 2.63 \\
\hline
\end{tabular}




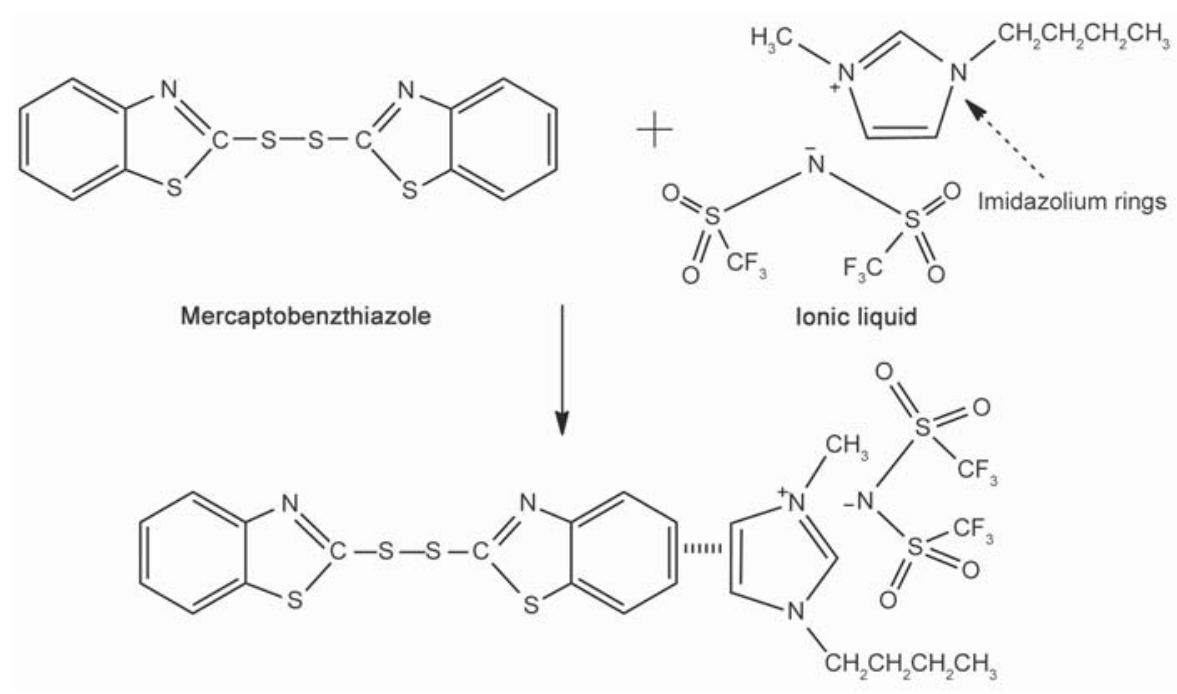

Figure 4. A proposed reaction mechanism between MBTS and 1-butyl-3-methyl imidazolium bis (trifluoromethylsulphonyl) imide (BMI) during vulcanization.

matrix, which increased the rate of sulfur vulcanization. On the other hand, addition of IL (BMI) and $\mathrm{CNT} / \mathrm{IL}$ prolonged $t_{\mathrm{s} 2}$ from that of the NR/CNT compound. This might be because BMI retarded vulcanization reactions by reacting with 2,2'-Dithiobis(benzothiazole) (MBTs) accelerator, as described in Figure 4. It is seen that the accelerator (MBT) can react with BMI via $\pi-\pi$ interactions between mercaptobenzthiazole and imidazolium rings. This would lower the reactivity of MBT in vulcanization of NR and delay scorch, as compared to the gum NR and NR/CNT compounds. However, in the NR/CNT-IL compound, the $t_{\mathrm{s} 2}$ and $t_{90}$ were significantly decreased from those of the gum NR compound due to the formation of CNT-IL (BMI) bridges that activated the vulcanization of the compound. Moreover, decreased $t_{\mathrm{s} 2}$ and $t_{90}$ might be due to reactions of CNTIL bridges with $\mathrm{NR}$ that consumed $\mathrm{C}=\mathrm{C}$ double bonds in NR by the reaction mechanism shown in Figure 2. Thus, active $\mathrm{C}=\mathrm{C}$ bonds in NR decreased and vulcanization of NR compounds had faster curing. This matches the disappearance of the IR absorption peak at $1643 \mathrm{~cm}^{-1}$, which is assigned to stretching vibrations of $-\mathrm{C}=\mathrm{C}-$ (Figure 1), upon addition of $\mathrm{CNT}$, IL and CNT-IL. In Table 3, it is also seen that the torque difference or delta torque increased with addition of CNT but decreased with addition of IL (BMI). This might be due to CNT network formation in the NR matrix, which increased crosslink density and reinforced the rubber vulcanizates. However, incorporation of imidazolium salt reduced torque by plasticizing and lubricating the rubber compound [31]. In addition, the IL (BMI) also acts as a retarder that delays vulcanization reactions of NR. Hence delta torque and crosslink densities of both NR/IL and NR/CNT-IL were below those of the gum NR and NR/CNT vulcanizates, because vulcanization was retarded by IL (BMI).

Kinetics of vulcanization was investigated by DSC performed at different heating rates $(q)$. The main aim was to analyze the exothermic temperature $\left(T_{\mathrm{p}}\right)$ for each heating rate. Then, the relationship between $\log q$ and $1 / T_{\mathrm{p}}$ (temperature) was plotted in accordance with the Ozawa equation (Equation (2)). The slope in $\log q$ versus $1 / T_{\mathrm{p}}$ plot was evaluated to estimate the activation energy $\left(E_{\mathrm{a}}\right)$ of vulcanization for each rubber sample, as follows [32]:

$E_{\mathrm{a}}=-2.3 R \frac{\mathrm{d} \log q}{\mathrm{~d}\left(\frac{1}{T_{p}}\right)}$

where $R$ is the gas constant $(8.31 \mathrm{~J} /(\mathrm{K} \cdot \mathrm{mol})), T_{\mathrm{p}}$ is the temperature at the exothermic peak and $q$ is the heating rate.

Figure 5 shows the relationships of $\log q$ and $1 / T_{\mathrm{p}}$ with $E_{\mathrm{a}}$ indicated for each curve. Also, the insert in Figure 5 shows the DSC thermogram of each rubber sample. Furthermore, Table 4 summarizes the activation energy and conversion for the gum NR vulcanizate and the NR filled with CNT, IL and CNT-IL, at each heating rate. It can be seen that the activation energies $\left(E_{\mathrm{a}}\right)$ of gum NR, CNT, IL and CNT-IL filled NR vulcanizates are 87.17, 124.36, 100.07 and $113.13 \mathrm{~kJ} / \mathrm{mol}$, respectively (Table 4). A higher $E_{\mathrm{a}}$ means the compound needs more energy to start vulcanization. It is seen in Figure 5 and Table that the gum NR had the lowest activation energy, while 


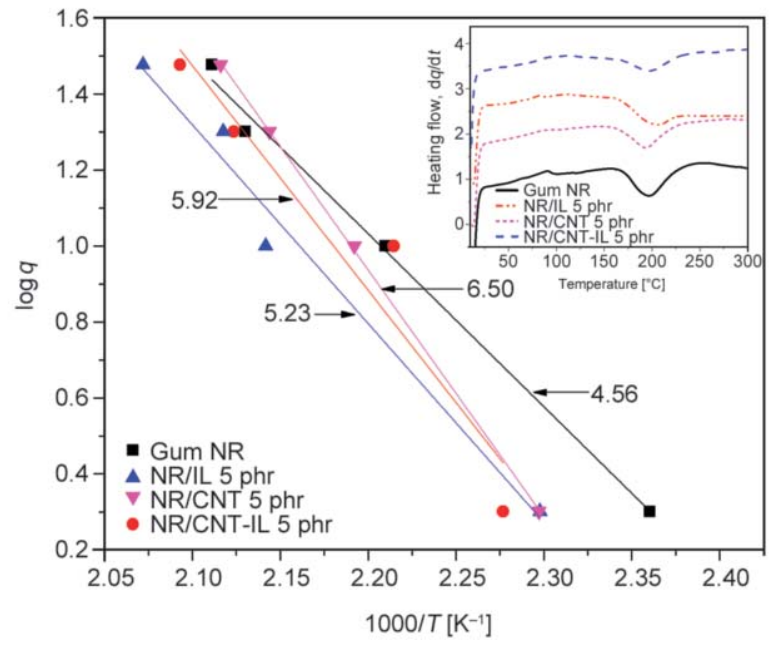

Figure 5. Relationship between $\log q$ and $1 / T_{\mathrm{p}}$ for the gum NR compound together with NR/CNT, NR/IL and NR/CNT-IL composites.

incorporation of CNT, IL and CNT-IL increased the activation energy of vulcanization. This might be due to CNT hindering reactions of active sulfur atoms and $\mathrm{C}=\mathrm{C}$ doubles bonds, by adsorbing polymer chains on the CNT surfaces (i.e., rubber-filler interactions) and by CNT and IL interfering with the accelerator molecules [33]. In NR/IL compound, a higher activation energy was observed because the IL (BMI) interact with $\mathrm{MBT}$ accelerator. Also, the alkyl chains in BMI could interact with NR via Van-der Waals forces [34]. This could hinder the vulcanization in NR/IL compound requiring more energy to start vulcanization than in the gum NR compound. It is also seen in
Table 4 that the NR/CNT-IL compound showed activation energy between NR/CNT and NR/IL compounds. This may relate to the absorption of rubber on CNT surfaces increasing activation energy. In addition, lower $E_{\mathrm{a}}$ was found for the NR/CNT-IL compound than for the NR/CNT compound. This might be attributed to finer dispersion for CNT in the rubber matrix in the NR/CNT-IL compound. This is because the IL (BMI) acted as a plasticizer or dispersing agent for CNT in NR matrix, improving the dispersion of CNT. This might reduce the activation energy of vulcanization reactions.

Degree of conversion by vulcanization can be estimated from the exothermic peaks in DSC thermograms according to Equations (3) and (4) [35]:

$$
\propto(T)=\frac{\Delta H_{\text {part }}}{\Delta H_{\text {tot }}} \cdot 100
$$

$$
=\frac{\int_{T_{0}}^{T} \emptyset(T) \mathrm{d} T}{\int_{T_{0}}^{T_{1}} \emptyset(T) \mathrm{d} T}
$$

where $\Delta H_{\text {part }}$ is the partial area of the DSC peak below the actual temperature, and $\Delta H_{\text {tot }}$ is the total area of the peak. $T_{0}$ and $T_{1}$ are the initial and end temperatures of reaction, respectively.

Figure 6 shows the degree of conversion of gum NR, together with CNT, IL and CNT-IL filled NR

Table 4. Activation energy and conversion of the gum NR compound together with NR/CNT, NR/IL and NR/CNT-IL com-

\begin{tabular}{|c|c|c|c|c|c|c|}
\hline Sample & $\begin{array}{c}\text { Heating rate } \\
{\left[{ }^{\circ} \mathrm{C} / \mathrm{min}\right]}\end{array}$ & $\begin{array}{c}T_{\mathrm{p}} \\
{\left[{ }^{\circ} \mathbf{C}\right]}\end{array}$ & $\begin{array}{c}E_{\mathrm{a}} \\
{[\mathrm{kJ} / \mathrm{mol}]}\end{array}$ & $\begin{array}{c}T_{0} \\
{\left[{ }^{\circ} \mathbf{C}\right]}\end{array}$ & $\begin{array}{c}T_{1} \\
{\left[{ }^{\circ} \mathrm{C}\right]}\end{array}$ & $\begin{array}{c}\text { Conversion } \\
{[\%]}\end{array}$ \\
\hline \multirow{4}{*}{ Gum NR } & 2 & 150.52 & \multirow{4}{*}{87.17} & 126 & 209 & \multirow{4}{*}{50} \\
\hline & 10 & 179.37 & & 152 & 223 & \\
\hline & 20 & 196.32 & & 158 & 234 & \\
\hline & 30 & 200.51 & & 166 & 236 & \\
\hline \multirow{4}{*}{ NR/IL 5 phr } & 2 & 162.06 & \multirow{4}{*}{100.07} & 125 & 176 & \multirow{4}{*}{51} \\
\hline & 10 & 193.75 & & 146 & 230 & \\
\hline & 20 & 199.06 & & 156 & 237 & \\
\hline & 30 & 209.49 & & 160 & 246 & \\
\hline \multirow{4}{*}{ NR/CNT 5 phr } & 2 & 162.16 & \multirow{4}{*}{124.30} & 108 & 209 & \multirow{4}{*}{82} \\
\hline & 10 & 183.02 & & 124 & 237 & \\
\hline & 20 & 193.31 & & 134 & 256 & \\
\hline & 30 & 199.42 & & 158 & 240 & \\
\hline \multirow{4}{*}{ NR/CNT-IL 5 phr } & 2 & 166.05 & \multirow{4}{*}{113.13} & 126 & 209 & \multirow{4}{*}{65} \\
\hline & 10 & 178.39 & & 152 & 223 & \\
\hline & 20 & 197.74 & & 158 & 234 & \\
\hline & 30 & 204.62 & & 166 & 236 & \\
\hline
\end{tabular}
posites. 


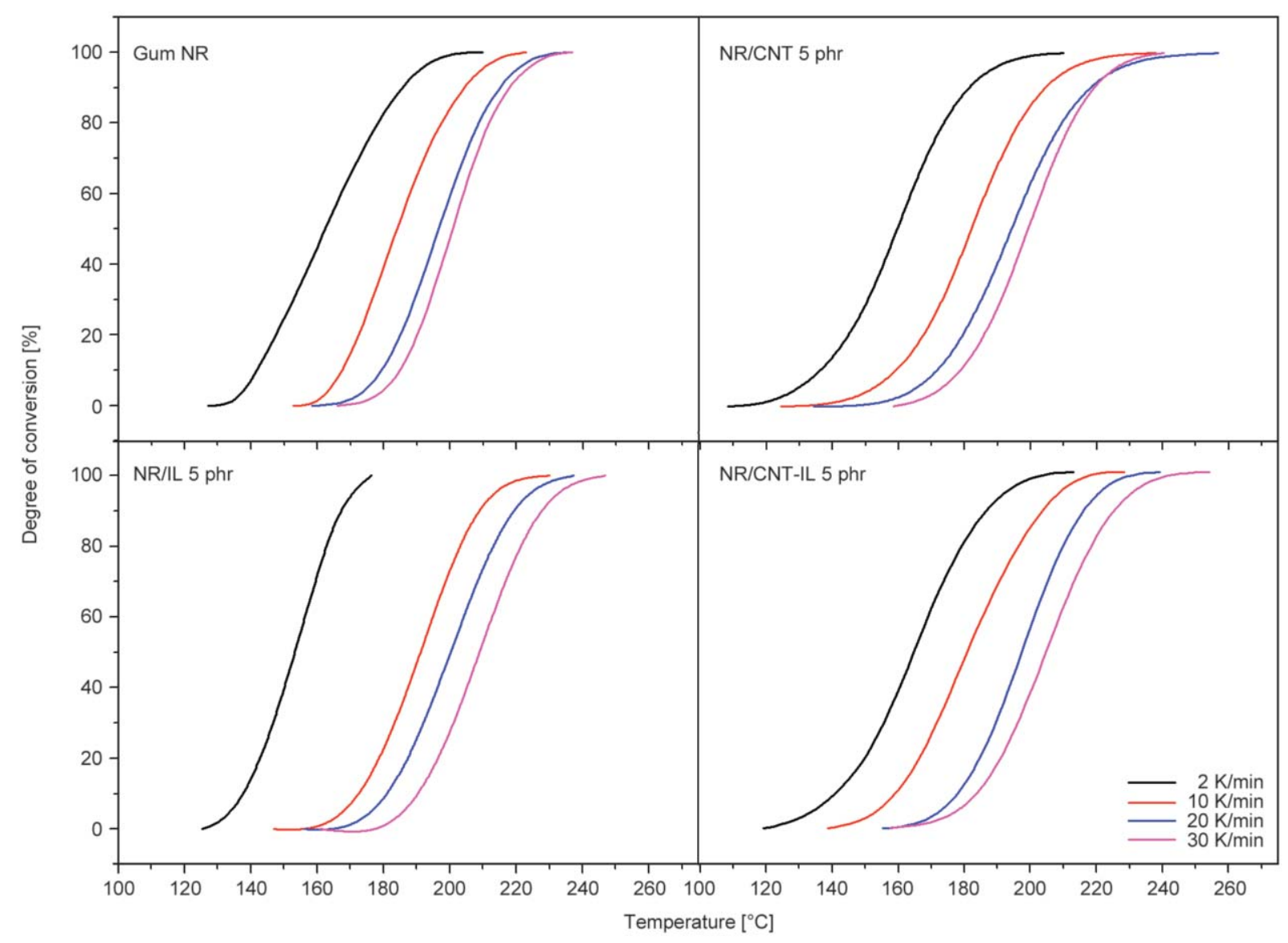

Figure 6. Conversion of the gum NR compound together with NR/CNT, NR/IL and NR/CNT-IL composites.

compounds. Also, Table 4 shows the conversion degrees of the various compounds estimated from Figure 6 and Equations (3) and (4). It can be seen that the gum NR together with NR/CNT, NR/IL and NR/CNT/IL compounds had degrees of conversation of $50,82,51$ and $65 \%$, respectively. Therefore, it is clear that the NR/IL (BMI) compound showed similar degree of conversion by vulcanization as the gum NR compound. On the other hand, the CNT effectively increased the degree of conversion (i.e., $82 \%$ ) probably by good thermal conduction and diffusion in the NR matrix [36], so that at the regular vulcanization temperature a higher degree of conversion was found than for the gum NR compound. Furthermore, the NR/CNT-IL compound showed less conversion than the NR/CNT compound, because IL (BMI) may cover CNT surfaces effectively preventing thermal diffusion along CNT, and may deactivate MBT by reactions with the IL (BMI). In summary, CNT in the NR matrix increases the energy required to vulcanize the rubber (higher $E_{\mathrm{a}}$ ), from that of the gum NR compound. However, shorter $t_{\mathrm{s} 1}$ and $t_{90}$ were found owing to the high thermal conductivity of CNT that increased the degree of conversion. These properties were significantly altered after CNT-IL was incorporated into the NR compound. That is, the vulcanization started later than for the NR/CNT compound (i.e., higher $t_{\mathrm{s} 2}$ ). This might be due to reactions of imidazolium rings with accelerator retarding vulcanization, as shown in Figure 4. This reduces $E_{\mathrm{a}}$ and the conversion by vulcanization, as seen in Figures 5 and 6, and Tables 3 and 4.

\subsection{Payne effect}

Figure 7 shows the storage modulus as a function of strain amplitude for the gum NR, together with CNT, IL and CNT/IL filled NR compounds. It can be seen that incorporation of IL lowers the storage moduli from that of the gum NR compound due to the plasticizing effect of IL [31]. However, the addition of CNT in NR showed the reverse effect by abrupt increase of the storage modulus for the NR/CNT composite. Moreover, the NR/CNT-IL composite showed a surprising synergy with the highest storage modulus. This might be due to the fine dispersion of CNT in the NR matrix. The dipole-dipole and $\pi-\pi$ interactions between CNT and BMI decreased re-agglomeration of CNT bundles [7]. It is noted that the Payne 


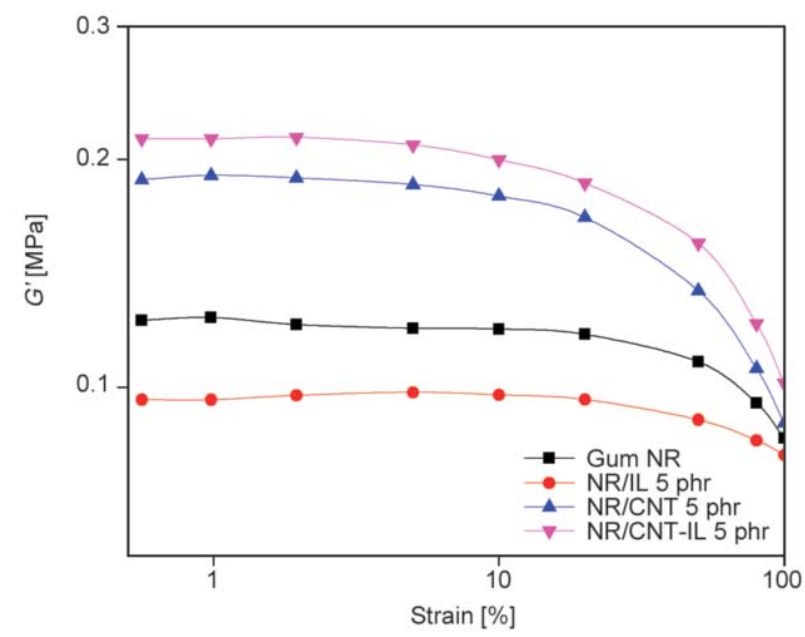

Figure 7. Storage modulus as a function of strain amplitude for the gum NR compound together with NR/CNT, NR/IL and NR/CNT-IL composites.

effect of filled rubber compounds can be assessed from the dynamic storage modulus $\left(G^{\prime}\right)$ at various strain amplitudes. It indicates the filler-filler and fillerrubber interactions in a rubber composite. Furthermore, the Payne effect in CNT-filled NR compounds could inform about CNT network formation [13]. The $G^{\prime}$ modulus tends to decrease with strain as the extension breaks filler networks [13], and a decreasing trend of $G^{\prime}$ at high applied strains is observed in Figure 7 also for the gum NR vulcanizate without any filler. This might be caused by the breakdown of NR crosslinks and entanglements [14]. It is noted that the Payne effect is typically estimated from moduli at very low and at very high strains $\left(G_{0}^{\prime} \rightarrow G^{\prime}\right)$ [37] as Equations (5) and (6):

$\Delta G^{\prime}=G_{0}^{\prime}-G_{\infty}^{\prime}$

$\% \Delta G^{\prime}=\frac{G_{0}^{\prime}-G_{\infty}^{\prime}}{G_{\infty}^{\prime}} \cdot 100$

where $G_{0}^{\prime}$ and $\mathrm{G}_{\infty}^{\prime}$ are the maximum and minimum moduli.

Table 5 shows the $\Delta G^{\prime}$ (Eq. (5)) and $\% \Delta G^{\prime}$ (Eq. (6)) of gum NR together with CNT, IL and CNT-IL filled
NR compounds as the Payne values for the filled NR compounds. It is noted that, to observe the Payne effect for the filled NR composites, the effects of NR matrix alone are canceled, so that the Payne effect [\%] of NR/CNT composite $=\% \Delta G_{\mathrm{NR} / \mathrm{CNT}}^{\prime}-\% \Delta G_{\text {Gum NR }}^{\prime}$ and the Payne effect [\%] of NR/CNT-IL composite $=$ $\% \Delta G_{\text {NR/CNT-IL }}^{\prime} \% \Delta G_{\text {NR/LL }}^{\prime}$, giving 68 and $88 \%$, respectively. It is noted that a larger Payne effect indicates more filler-filler interactions. Furthermore, it has been claimed that a finer dispersion of CNT also increases the Payne effect in rubber/CNT/ionic liquid hybrid composites [28]. Therefore the combination of CNT and IL that improved the CNT dispersion and gave larger Payne effect, as in the model of Figure 8. It can be seen that chain entanglement of NR molecules occurs due to the high molecular weight and coil-like conformations, as shown in Figure 8a. This is reflected by the about $44 \% \% \Delta G^{\prime}$ of the gum NR compound (Table 5). However, addition of IL in the NR matrix reduced $\% \Delta G^{\prime}$ by about $23 \%$ (Table 5 ). This might be due to plasticizing effect of the IL (BMI) that reduced physical interactions (friction) of NR molecules and allowed slippage and disentanglement, as described in Figure 8b. Furthermore, the addition of CNT in NR increased $\% \Delta G^{\prime}$ by increasing filler-filler interactions of CNT bundles, as described in Figure 8c. Moreover, the largest Payne effect was observed for the NR/CNT-IL composite. This might be attributed to the $\pi-\pi$ interactions of alkyl chains in BMI and CNT that broke down CNT bundles. This means that the CNT particles could interact with each other, producing a strong Payne effect, as shown in Figure 8d. Likewise, the imidazolium rings in BMI interacted with the CNT particles via $\pi-\pi$ interactions, as described in Reaction B (Figure 2). Therefore, the alkyl chains in IL (BMI) might expand CNT bundles by diffusing into them. However, the IL (BMI) might reduce filler-filler interactions of CNT but still strongly affect the CNT network formation in NR/CNT-IL composites. This gave the strongest Payne effect for the NR/CNT-IL composites.

Table 5. Payne effect (calculated from Equations (6) and (7)) for the gum NR compound together with NR/CNT, NR/IL and NR/CNT-IL composites.

\begin{tabular}{|l|c|c|c|c|c|}
\hline \multicolumn{1}{|c|}{ Sample } & $\begin{array}{c}\boldsymbol{G}_{\mathbf{0}}{ }^{\prime} \\
{[\mathbf{M P a}]}\end{array}$ & $\begin{array}{c}\mathbf{G}_{\infty}{ }^{\prime} \\
{[\mathbf{M P a}]}\end{array}$ & $\begin{array}{c}\Delta \boldsymbol{G}^{\prime} \\
{[\mathbf{M P a}]}\end{array}$ & $\begin{array}{c}\Delta \boldsymbol{G}^{\prime} \\
{[\%]}\end{array}$ & $\begin{array}{c}\text { Payne effect of filled NR } \\
{[\%]}\end{array}$ \\
\hline Gum NR & 0.1236 & 0.08570 & 0.0379 & 44 & - \\
\hline NR/IL 5 phr & 0.0997 & 0.08140 & 0.0183 & 23 & - \\
\hline NR/CNT 5 phr & 0.1905 & 0.08970 & 0.1008 & 112 & 68 \\
\hline NR/CNT-IL 5 phr & 0.2138 & 0.10124 & 0.1126 & 111 & 88 \\
\hline
\end{tabular}

Payne effect was calculated based on Equations (6) and (7). 
a)

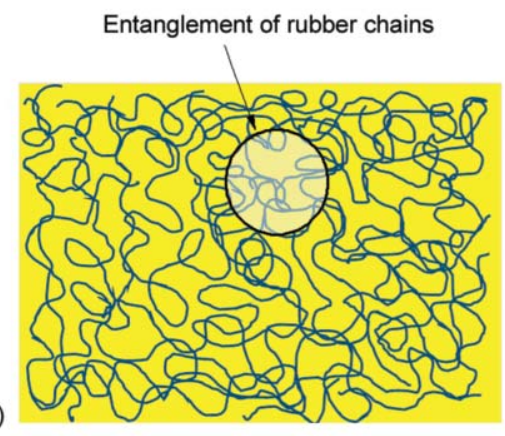

c)

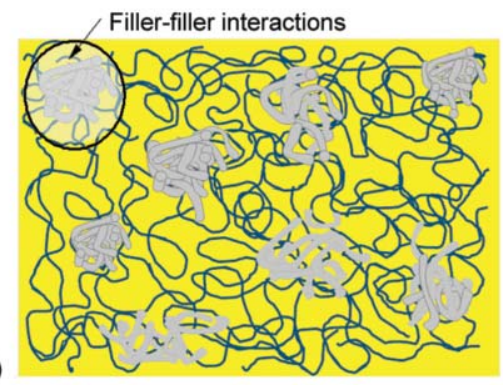

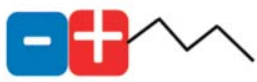

Ionic liquid molecule

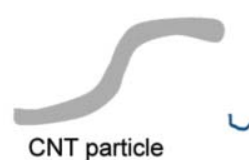

d)

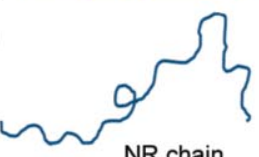

b)

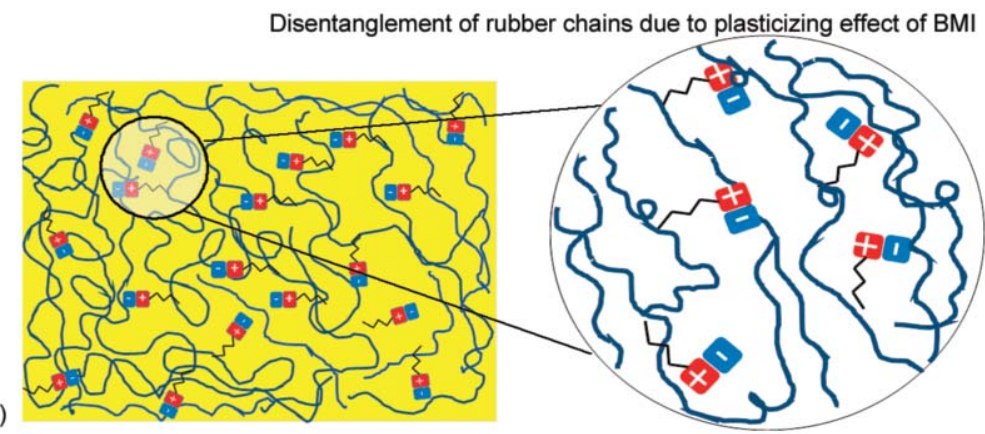

Figure 8. A proposed model for chain entanglement of natural rubber molecules (a), and NR filled with IL (b), CNT (c) and CNT-IL (d).

\subsection{Temperature scanning stress relaxation (TSSR)}

Relaxation behavior under thermal treatment of the gum NR compound together with IL, CNT and CNT-IL filled NR compounds was characterized by the novel TSSR technique. The TSSR curves, or the relations of stress relaxation to temperature, are shown in Figure 9. Also, Table 6 summarizes the TSSR results in terms of initial stress $\left(\sigma_{0}\right)$ and relaxation temperature $\left(T_{\mathrm{x}}\right)$. It is noted that the $T_{\mathrm{x}}$ stands for the temperature at which the force has decreased by $x \%$ from its initial value $\left(F_{0}\right)$ [38]. Thus, $T_{10}, T_{50}$ and $T_{90}$ indicate the temperatures at which the stresses have decreased by 10,50 and $90 \%$ from the initial stress. In Figure 9, it can be seen that addition of IL increased the stress in NR/IL compound from that of the gum NR compound. In contrast, the plasticizing effect of IL (BMI) should give a lower stress. However, the IL (BMI) can act differently in un-vulcanized and vulcanized NR/IL compounds. That is, the IL (BMI) decreased the torque difference (Figure 3 and Table 3) and storage modulus (Figure 7 and Table 5) in un-vulcanized natural rubber compounds, but gave higher stiffness in the NR/IL vulcanizate. This might be due to the random localization of BMI

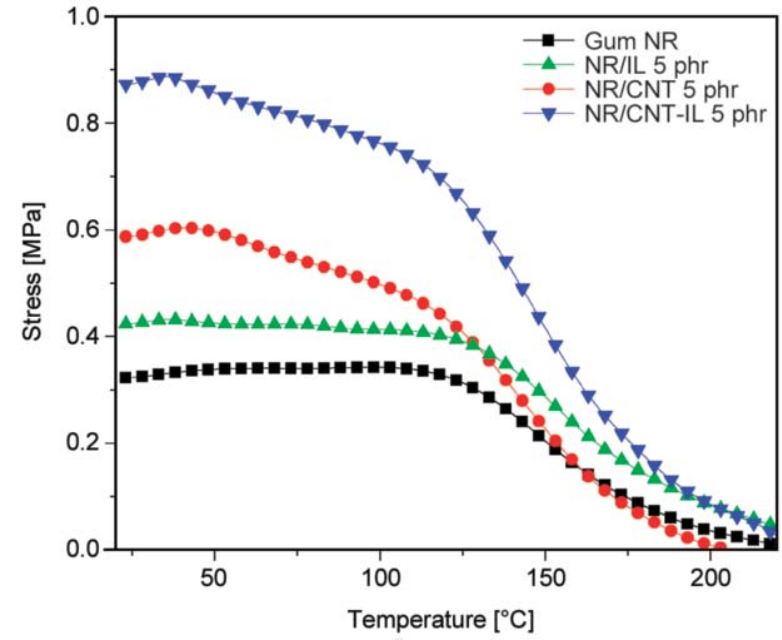

Figure 9. Stress relaxation of the gum NR compound together with NR/CNT, NR/IL and NR/CNT-IL composites.

Table 6. TSSR results in terms of and Tx for the gum NR compound together with NR/CNT, NR/IL and NR/CNT-IL composites.

\begin{tabular}{|l|c|c|c|c|}
\hline \multicolumn{1}{|c|}{ Sample } & $\begin{array}{c}\boldsymbol{\sigma}_{\mathbf{0}} \\
{[\mathbf{M P a}]}\end{array}$ & $\begin{array}{c}\boldsymbol{T}_{\mathbf{1 0}} \\
{\left[{ }^{\circ} \mathbf{C}\right]}\end{array}$ & $\begin{array}{c}\boldsymbol{T}_{\mathbf{5 0}} \\
{\left[{ }^{\circ} \mathbf{C}\right]}\end{array}$ & $\begin{array}{c}\boldsymbol{T}_{\mathbf{9 0}} \\
{\left[{ }^{\circ} \mathbf{C}\right]}\end{array}$ \\
\hline Gum NR & 0.32 & 132.0 & 158.6 & 202.1 \\
\hline NR/IL 5 phr & 0.42 & 128.8 & 163.2 & 220.0 \\
\hline NR/CNT 5 phr & 0.59 & 84.2 & 141.3 & 181.0 \\
\hline NR/CNT-IL 5 phr & 0.87 & 89.1 & 148.1 & 199.3 \\
\hline
\end{tabular}




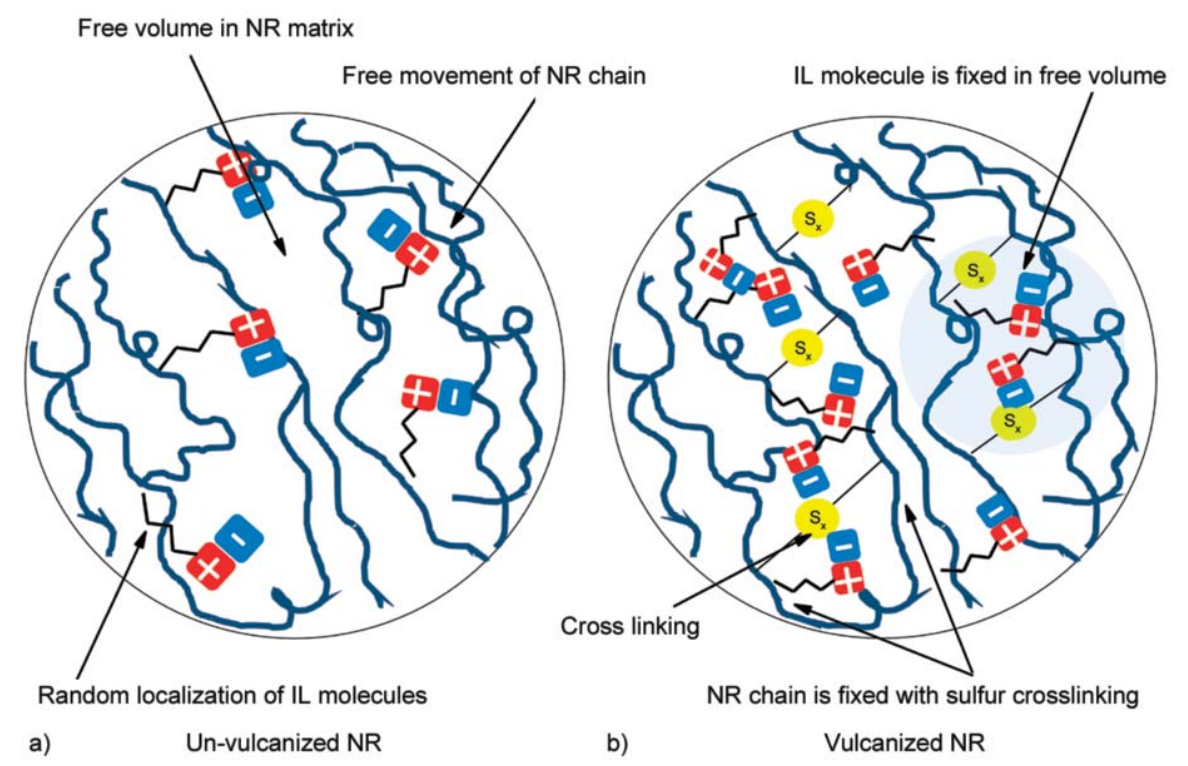

Figure 10. A proposed model for the localization of IL in un-vulcanized (a), and in vulcanized NR samples (b).

molecules that can link to NR molecules via sulfur linkages, as described in Figure 10. That is, the IL in the NR matrix could freely move and lubricate the NR molecular chains during shear deformation of the un-vulcanized NR sample. On the other hand, after vulcanization of NR, the IL (BMI) formed small domains dispersed in the NR matrix. Hence, the restriction of molecular movement was due to the sulfur crosslinks [39], as seen in Figure 10b.

It is also seen in Figure 9 that the stress-temperature curve of NR/CNT is above that of the gum NR vulcanizate, particularly at temperatures below $150^{\circ} \mathrm{C}$. This indicates the reinforcement effect of CNT in the NR matrix. Moreover, the combination of CNT and IL in NR vulcanizate (i.e., NR/CNT-IL) showed the highest stress-temperature curve. This might be due to the IL (BMI) effectively improving the dispersion of CNT so that stronger three-dimensional networks of CNT were produced. In Figure 9, it is also seen that the initial gradient of the stress-temperature curve slightly increased, due to the entropy effect of NR similar to other crosslinked networks or gels [19]. Therefore, it is clear that incorporation of CNT and CNT-IL increased the entropic effect from that in the gum NR vulcanizate. This might be attributed to more physical interactions of NR that was adsorbed on the CNT surfaces [5]. It is clear in Figure 9 that a plateau stress-temperature relation was observed in the temperature range from 50 to $120^{\circ} \mathrm{C}$ for the gum NR and $\mathrm{NR} / \mathrm{IL}$ vulcanizates. On the other hand, the NR/CNT and NR/CNT-IL composites showed a slightly decreasing stress with temperature in this range. This

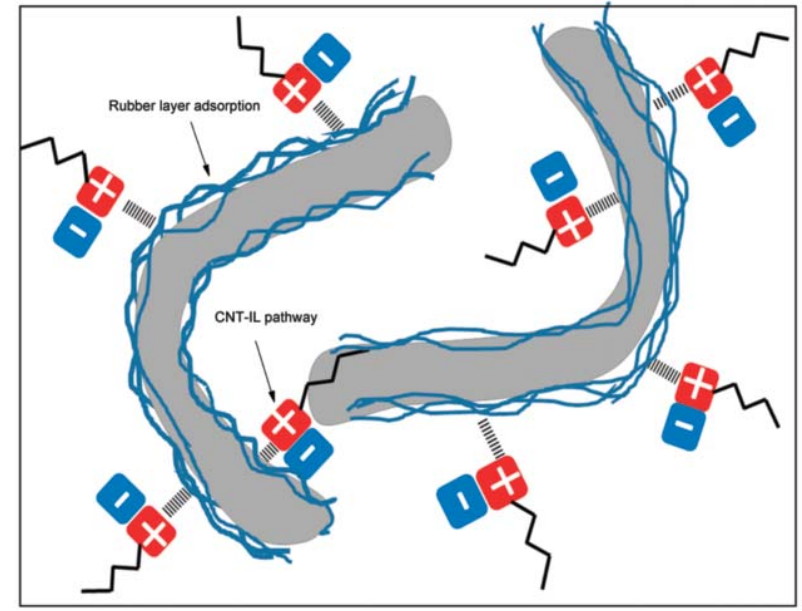

Figure 11. A proposed model of adsorbed rubber layer and its breakdown in NR/CNT-IL composite.

might be due to the breakdown of some physically adsorbed rubber layers on CNT surfaces [8], as depicted in Figure 11. It can be seen that the rubber chains reacted with CNT particles and NR was deposited on CNT surfaces. Also, the IL (BMI) could interact with $\mathrm{CNT}$ via dipole-dipole interactions. However, the weak interactions of NR with CNT or CNT-IL might be degraded at elevated temperatures from 50 to $120^{\circ} \mathrm{C}$.

Furthermore, stress relaxation was clearly observed for temperatures of $120-220^{\circ} \mathrm{C}$ in all samples studied. This might be due to the thermo-oxidative degradation of rubber [40]. In Table 6, it is also seen that the lowest $T_{10}$ (i.e., the temperature at which the force has decreased by $10 \%$ from the initial force) was observed for the NR/CNT composite, while the highest 
was for the gum NR and NR/IL vulcanizates. This might be related to the higher thermal conductivity of NR/CNT compound that favored thermal stress relaxation. Also, the physical desorption of rubber adsorbed on CNT might also play an important role. In addition, the NR/IL composite exhibited the highest $T_{50}$ and $T_{90}$, which indicate better thermal resistance of the NR. This might be attributed to the high thermal stability of IL (BMI) [7] that improved thermo-oxidative resistance of the rubber composite. In contrast, the NR/CNT composites exhibited the lowest $T_{50}$ and $T_{90}$ due to high thermal conductivity and thermal diffusion in CNT, which facilitated thermooxidative degradation of NR $[23,30]$. However, the combination of CNT-IL improved thermal stability due to the proper combination of high thermal stability of IL (BMI) and high thermal conductivity of CNT, as described in Figure 11. It is seen that the phonon charges had freedom of movement along the NR matrix through the CNT network in the NR/CNT composite. This induced faster thermo-oxidative degradation at $T_{50}$ and $T_{90}$ in the NR/CNT than in the NR/CNT-IL composite [30]. As expected, the CNT surfaces might be covered by high thermal stability IL (BMI), which caused scattering of phonon ions in the CNT-IL pathway, as shown in Figure 11. Thus, thermal diffusion was limited and therefore the $T_{50}$ and $T_{90}$ of NR/CNT-IL composites were higher than for the NR/CNT composite.

The relaxation spectrum $(H(T))$ was obtained by differentiating the non-isothermal relaxation modulus $(E(T))$, it is per definition calculated from the stress ' $\sigma$ ' by devision of the applied constant strain ' $\varepsilon$ ' (in this case $\varepsilon=0.5(50 \%)$ for a constant heating rate $\left(v=2{ }^{\circ} \mathrm{C} / \mathrm{min}\right)$, as Equations (7) and (8) [41, 42]:

$$
\begin{aligned}
& E=\frac{\sigma}{\varepsilon_{0}} \\
& H(T)=-T\left[\frac{\mathrm{d} E(T)}{\mathrm{d} T}\right]_{\mathrm{V}=\text { const }}
\end{aligned}
$$

where $\sigma$ is the stress at a given time $(t)$ or temperature $(T)$ and $\varepsilon_{0}$ is the applied strain, which is kept constant.

Figure 12 shows the relaxation spectra of gum NR compound, together with CNT, IL and CNT-IL filled NR compounds, with a magnification of the spectra for the temperature range $23-220^{\circ} \mathrm{C}$. It can be seen that the NR/CNT composites showed the higher relaxation peaks than the gum NR compound. This

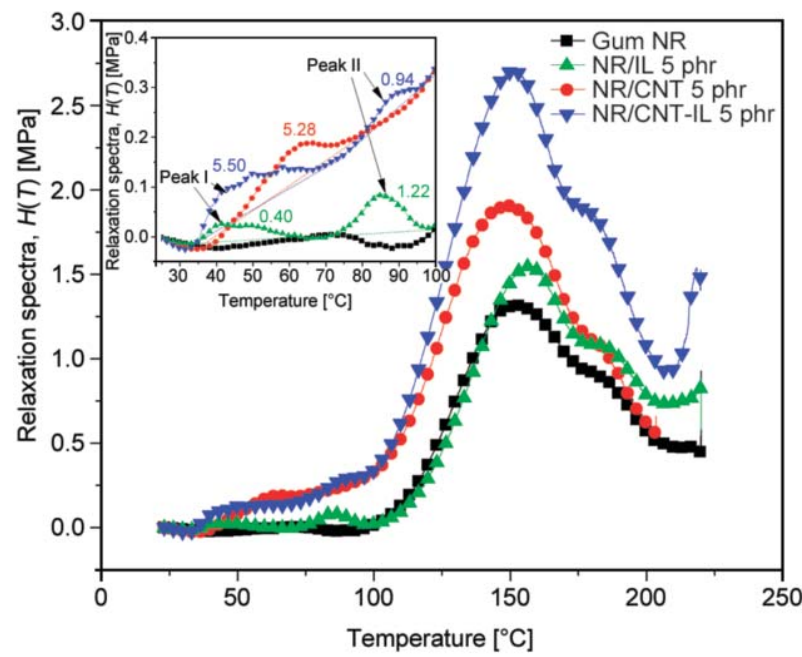

Figure 12. Relaxation spectrum of the gum NR vulcanizate together with NR/CNT, NR/IL and NR/CNT-IL composites, with magnified temperature range $23-100^{\circ} \mathrm{C}$ in the in the left corner.

might be attributed to more rubber-filler and fillerfiller interactions in the CNT filled NR compound. Furthermore, two relaxation peaks were observed in NR/IL and NR/CNT-IL composites in the temperature range $23-100^{\circ} \mathrm{C}$. That is, peak $I$ is in the temperature range $35-60^{\circ} \mathrm{C}$, while peak $I I$ is in the temperature range $70-100^{\circ} \mathrm{C}$. It is noted that peak I might be attributed to the desorption of physically bound rubber, while peak II might be assigned to the degradation of IL (BMI) molecules. In addition, each compound showed a relaxation peak in the temperature range $100-200^{\circ} \mathrm{C}$, which indicates relaxation of NR. It is clear that the addition of filler increased relaxation peak intensity, with a synergistic effect in the NR/CNT-IL composite. This might be due to stronger interactions or bonds between NR and CNT. Furthermore, the IL by improving the dispersion of CNT may have enabled stronger three-dimensional CNT networks, which increased the relaxation energy, as described in Figure 8d.

\subsection{Electrical properties}

Figure 13 shows electrical conductivity of IL, CNT and CNT-IL filled NR vulcanizates with various filler loadings. Normally, the electrical conductivity of a composite with conductive filler has a percolation threshold concentration $\left(f_{\mathrm{c}}\right)$, which is the critical filler concentration that suffices for conductive pathways through the insulating matrix [43]. The percolation threshold concentration $\left(f_{\mathrm{c}}\right)$ can be estimated using percolation theory Equations (9) and (10) [44]: 
$\sigma_{\mathrm{DC}}=k\left(f-f_{\mathrm{c}}\right)^{t}, f>f_{\mathrm{c}}$

$\log \sigma_{\mathrm{DC}}=\log k+t \cdot \log \left(f-f_{\mathrm{c}}\right)$

where $\sigma_{\mathrm{DC}}$ is the $D C$ conductivity of the composite, the parameters $f$ and $f_{\mathrm{c}}$ are the volume fraction of filler and the volume fraction at percolation threshold, respectively, $k$ is a constant and parameter $t$ is related to the type of network formed by the filler in the matrix.

In Figure 13, it is clearly seen that adding IL in NR slightly increased electrical conductivity, but the loading level of IL (BMI) had no significant effect the conductivity of an NR vulcanizate. This might be because the IL (BMI) was encapsulated by the insulating NR as the imidazolium IL could be more compatible with the hydrophobic rubber matrix [7]. This leads to the poor electrical conductivity of the NR/IL vulcanizate, with no detectable percolation threshold. On the other hand, the NR/CNT and NR/CNT-IL composites showed percolation threshold concentrations (based on Equations (9) and (10)) at 3.64 and $2.92 \mathrm{phr}$, respectively. Therefore, the NR/CNT-IL composite exhibited comparatively high electrical conductivity with lower percolation threshold than in the NR/CNT composites. This might be due to the synergy of plasticizing by IL (BMI) that contributed to good dispersion of CNT, which then could form three-dimensional networks in the NR matrix, assisted by the physical interactions of CNT particles, as described in Figure 2 (Reaction B). Therefore, the plasticizing effect and physical interactions facilitated CNT network formation and reduced CNT agglomeration, as shown in Figure 8d. This matches the Payne effect (Figure 7) and the initial stress relaxation (Figure 9) of the various NR vulcanizates.

\subsection{Thermal degradation}

Figures 14 and 15 show TGA and DTG thermograms of gum NR vulcanizate together with IL, CNT and CNT-IL filled NR vulcanizates. It is noted that TGA was performed under nitrogen atmosphere in the temperature range from 23 to $600^{\circ} \mathrm{C}$, with switching to oxygen atmosphere for the temperature range from 600 to $900^{\circ} \mathrm{C}$. It can be seen in Figure 14 that the NR/CNT and NR/CNT-IL composites show immediate weight losses at the initial temperature (a). This might be due to the thermal degradation of hydroxyl groups on the CNT surfaces in temperature range $100-200^{\circ} \mathrm{C}$ [45]. On the other hand, the NR/IL and gum NR vulcanizates showed no significant difference in the initial TGA thermograms. In addition, the NR/CNT and NR/CNT-IL composites still exhibited faster decomposition at the higher temperatures in region (b), which matches the DTG thermogram peaks $(i)$ in Figure 15. This might be due to the high thermal conductivity of CNT which enabled thermal diffusion in the composites and hence caused a faster thermo-oxidative degradation. Furthermore, the NR/IL composite showed slightly decreasing trend of weight in this region. This might be due to the thermal decomposition of short alkyl chains in the imidazolium molecules. Nevertheless, in the temperature region (c), the last region under the nitrogen atmosphere (Figure 14), it can be seen that the NR/CNT-IL composite exhibited the most residue, on comparing to
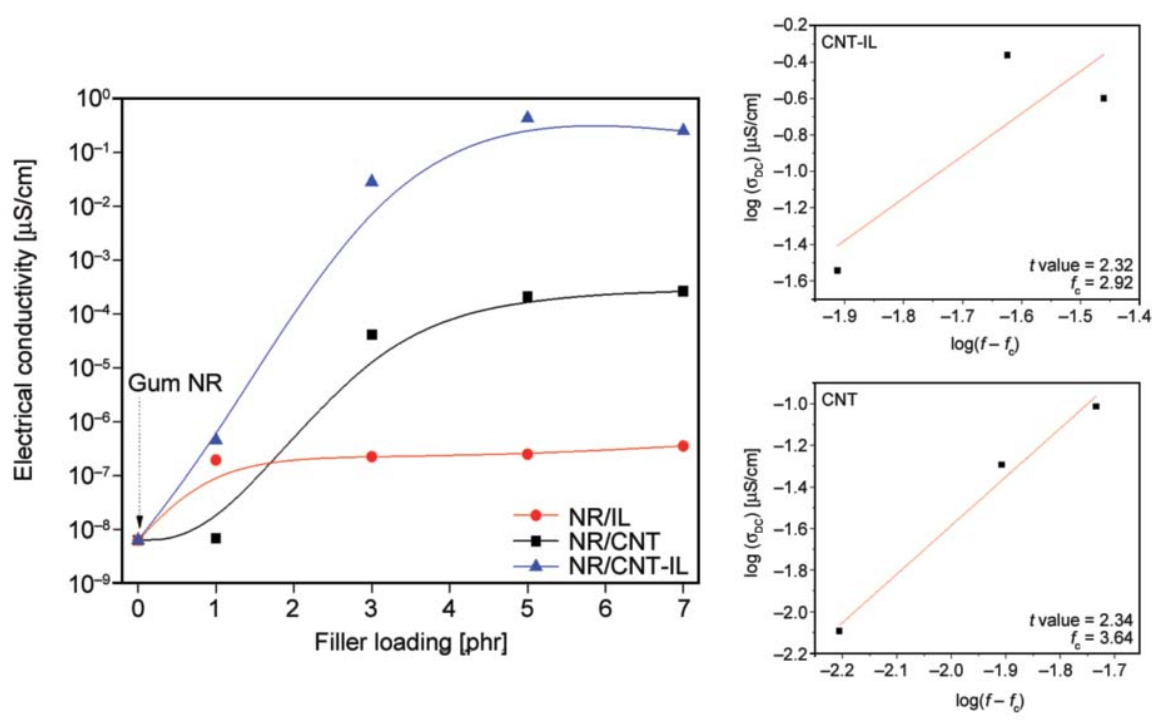

Figure 13. Electrical conductivity of NR/CNT, NR/IL and NR/CNT-IL vulcanizates with various filler loadings. 


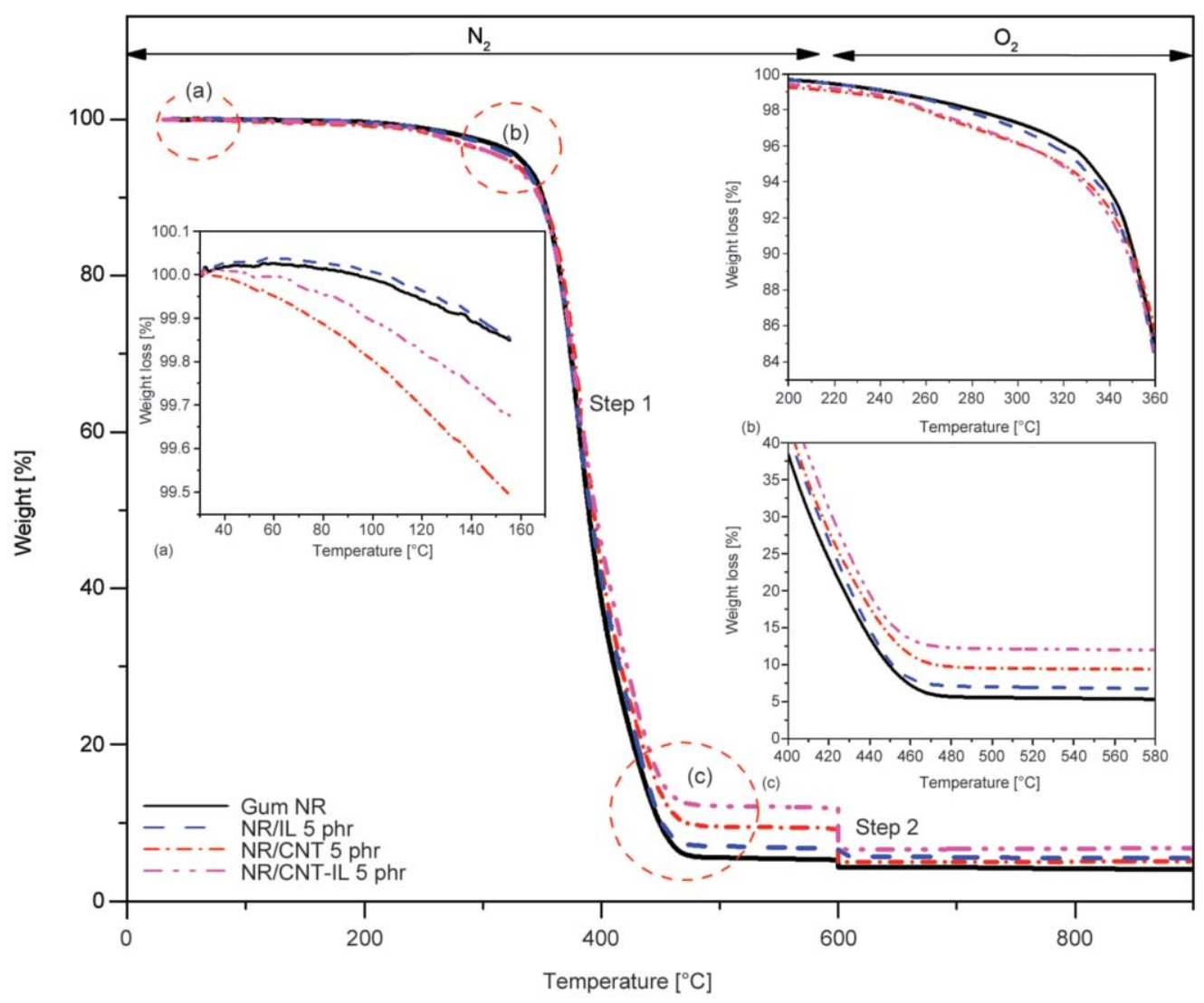

Figure 14. TGA thermograms of gum NR vulcanizate together with NR/CNT, NR/IL and NR/CNT-IL composites.

the NR/CNT and NR/IL composites. On the other hand, the gum NR vulcanizate exhibited the least residue. Therefore, the IL (BMI) improved CNT dispersion and three-dimensional networks in the NR matrix with more rubber-filler interactions in the NR/CNT-IL composite. This gave the highest residue amount after heating under nitrogen atmosphere until $600^{\circ} \mathrm{C}$. It is also seen in Figure 14 and Table 7

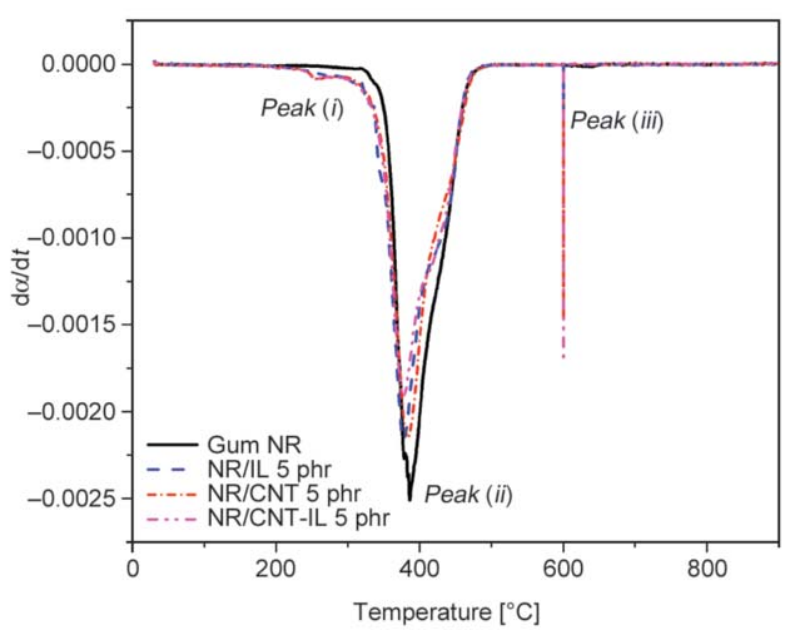

Figure 15. DTG thermograms of gum NR vulcanizate together with NR/CNT, NR/IL and NR/CNT-IL composites. that the decomposition temperature $\left(T_{\mathrm{d}}\right)$ of gum NR and NR composites are clearly established in the temperature range $385-390^{\circ} \mathrm{C}$, which is confirmed by the DTG thermograms, peak (ii). That is, the $T_{\mathrm{d}} \mathrm{S}$ of gum NR vulcanizate, and NR/IL, NR/CNT and NR/CNT-IL composites are $390.66,388.82,390.11$ and $385.33^{\circ} \mathrm{C}$, respectively.

In Table 7, it is also seen that weight losses of gum NR vulcanizate, as well as NR/CNT, NR/IL and NR/ CNT-IL composites under nitrogen atmosphere at the end of step I are $94.10,90.57,93.21$ and $88.10 \%$, respectively. It is noted that the weight loss arises from the decomposition of moisture and organic

Table 7. Weight loss and degradation temperature $\left(T_{\mathrm{d}}\right)$ for the gum NR compound together with NR/CNT, NR/IL and NR/CNT-IL composites.

\begin{tabular}{|l|c|c|c|c|}
\hline \multirow{2}{*}{ Step } & \multicolumn{4}{|c|}{ Weight loss } \\
\cline { 2 - 5 } & Gum NR & NR/CNT & NR/IL & NR/CNT-IL \\
\hline $\begin{array}{l}\text { Step 1 (under } \\
\mathrm{N}_{2} \text { atmosphere ) }\end{array}$ & 94.10 & 90.57 & 93.21 & 88.10 \\
\hline $\begin{array}{l}\text { Step 2 (under } \\
\mathrm{O}_{2} \text { atmosphere) }\end{array}$ & 0.83 & 4.35 & 0.91 & 5.26 \\
\hline & \multicolumn{4}{|c|}{ Degradation temperature $\left.\boldsymbol{(}_{\mathbf{d}}\right)$} \\
\cline { 2 - 5 } & 390.66 & 390.11 & 388.82 & 385.33 \\
\hline
\end{tabular}


components in the composites, in particular the NR molecules. It is clear that the gum NR vulcanizate showed the most weigh loss $(94.10 \%)$ while the NR/IL vulcanizate had $93.21 \%$. The gum NR vulcanizate had the most easily degraded NR while some of the NR was replaced by IL(BMI) in the NR/IL vulcanizate. The NR/CNT and NR/CNT-IL composites exhibited less weight loss at 90.57 and $88.10 \%$, respectively. This might be due to the high thermal conductivity of CNT promoting degradation in the NR/CNT composite while the NR/CNT-IL composite benefited from the low MW component IL (BMI). In Table 7, it is also seen that the decomposition under oxygen atmosphere could be correlated to the small but sharp DTG thermogram peaks (iii) in Figure 15. That is, the weight losses of gum NR, NR/IL, NR/CNT and NR/CNT-IL composites are $0.83,0.91,4.35$ and $5.26 \%$, respectively. The remaining char residues from gum NR vulcanizate (i.e, $0.83 \%$ ) might represent various inorganic minor components. In addition, the large weight losses of NR/CNT and NR/CNT-IL could be from degradation of CNT and/or IL together with other components under the oxygen atmosphere.

\subsection{Dynamic mechanical analysis (DMA)}

Figure 16 shows the storage modulus $\left(G^{\prime}\right)$ and the loss tangent $(\tan \delta)$ as functions of temperature for the gum NR vulcanizate together with NR/CNT, NR/IL and NR/CNT-IL composites. Also, Table 8 shows glass transition temperature $\left(T_{\mathrm{g}}\right)$ and $\tan \delta_{\max }$ for the same cases. Higher storage moduli were seen in the glassy regions of NR/CNT, NR/IL and NR/ CNT-IL composites than for the gum NR vulcanizate. This might be due to the reinforcement of NR

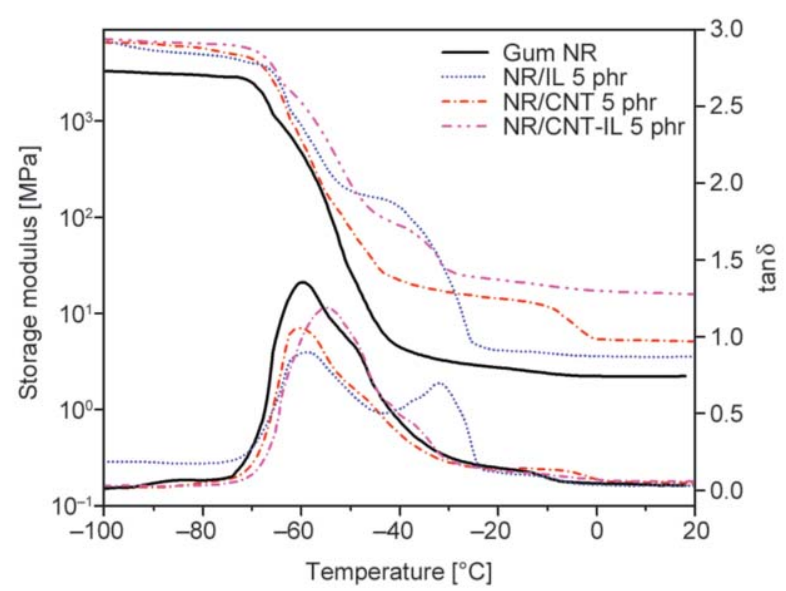

Figure 16. Storage modulus and $\tan \delta$ as functions of temperature for the gum NR compound together with NR/CNT, NR/IL and NR/CNT-IL composites.
Table 8. Glass transition temperature $\left(T_{\mathrm{g}}\right)$ and $\tan \delta_{\max }$ for the gum NR compound together with NR/CNT, NR/IL and NR/CNT-IL composites.

\begin{tabular}{|l|c|c|c|}
\hline \multicolumn{1}{|c|}{ Sample } & $\begin{array}{c}\boldsymbol{T}_{\mathbf{g} 1} \\
{\left[{ }^{\circ} \mathbf{C}\right]}\end{array}$ & $\begin{array}{c}\boldsymbol{T}_{\mathbf{g} 2} \\
{\left[{ }^{\circ} \mathbf{C}\right]}\end{array}$ & $\tan \boldsymbol{\delta}_{\max }$ \\
\hline Gum NR & -52.7 & - & 1.38 \\
\hline NR/IL 5 phr & -55.3 & -32.2 & 0.93 \\
\hline NR/CNT 5 phr & -55.8 & - & 1.09 \\
\hline NR/CNT-IL 5 phr & -51.4 & -36.5 & 1.18 \\
\hline
\end{tabular}

matrix by CNT and the mixture of CNT and IL. Likewise, the plasticizing effect of IL favored orientation of rubber molecules and the formation of three-dimensional CNT networks in the NR matrix.

In the glass transition state, the moduli of all samples abruptly decreased with temperature. It is clear that the composites with IL showed two decreasing stages while the ones without IL exhibited only a single stage of decreasing storage modulus. This correlates to the double $\tan \delta$ peaks of the composites with IL, but a single $\tan \delta$ peak for the composites without IL. This reflects the glass transitions of NR and BMI at different temperatures. Therefore, the gum NR compound and NR/CNT composite showed a single glass transition temperature $\left(T_{\mathrm{g}}\right)$ at -52.7 and $-55.8^{\circ} \mathrm{C}$, respectively. On the other hand, the NR/IL composite showed double $T_{\mathrm{g}} \mathrm{s}$ at -55.3 and $-32.2{ }^{\circ} \mathrm{C}$, which reflect the $T_{\mathrm{g}} \mathrm{s}$ of NR and IL (BMI) phases, respectively. Hybridization in the CNT-IL filled NR matrix shifted the $T_{\mathrm{g}}$ of NR phase to a higher temperature (i.e., $-51.4^{\circ} \mathrm{C}$ ) that was lower than the $T_{\mathrm{g}}$ of IL (BMI) at $-36.54^{\circ} \mathrm{C}$. It is noted that shift of $T_{\mathrm{g}}$ might be due to the amorphous structure of rubber chains [46]. In Table 8, it can be seen that addition of CNT or IL decreased $T_{\mathrm{g}}$ of the NR phase. This is due to the increased free volume in the NR matrix, from CNT agglomeration which left NR molecular chains to move freely [34]. Moreover, the plasticizing effect of IL (BMI) favors molecular mobility [34], which reduced the level of entanglements of NR molecules. However, the NR/CNT-IL composite showed higher $T_{\mathrm{g}}$ of NR phase but lower $T_{\mathrm{g}}$ of IL (BMI) phase. This might be due to the good filler-rubber interactions favoring formation of CNT networks. Thus, the NR molecular mobility or flexibility was restricted by the formed CNT networks. Moreover, the addition of CNT-IL shifted $T_{\mathrm{g}}$ of NR and IL (BMI) phases toward each other (i.e, the NR phase shifted to higher temperature while the IL (BMI) shifted to lower temperature). This suggests partial miscibility of the blend components [47]. In Table 8, it can be seen 
that the incorporation of CNT, IL, and especially CNT-IL hybrid filler in the NR matrix reduced $\tan \delta$ max or the energy loss, meaning worsened damping properties.

\subsection{Morphological properties}

Figure 17 shows SEM micrographs of NR/IL (BMI), NR/CNT and NR/CNT-IL composites. White spots (Figure 17a) and large cavities (Figure 17b) were dispersed in the NR matrix of the NR/IL vulcanizate. The white spots might be accumulated BMI (crystalline salt) and/or $\mathrm{ZnO}$ particles dispersed in the NR matrix. Also, pores or voids could be the result of incompatibility between NR and BMI. In addition, the sample preparation for SEM inspection by cryogenic fracturing in liquid nitrogen could cause cracks or fractures on sample surfaces. In Figure 17c, both CNT particles and agglomerates are clearly seen in

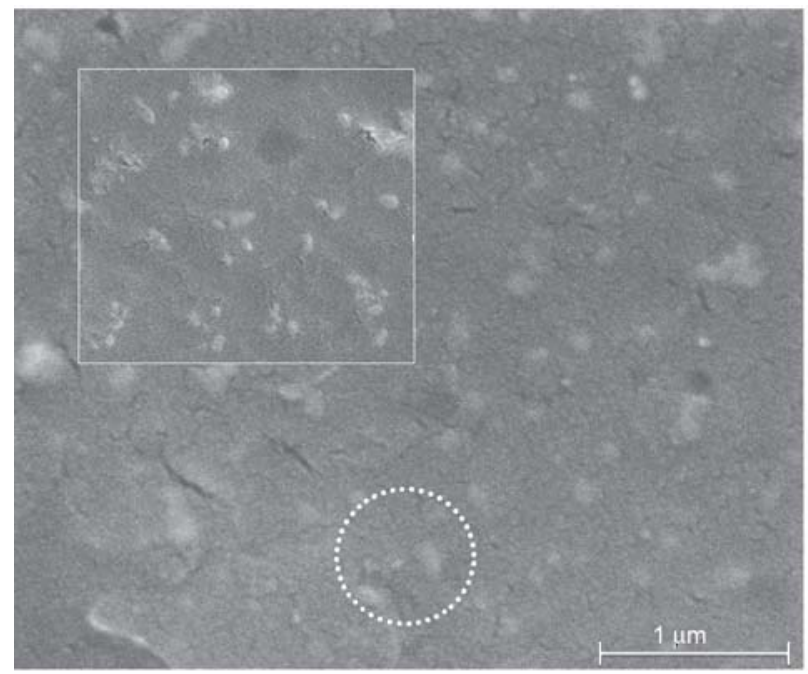

a)

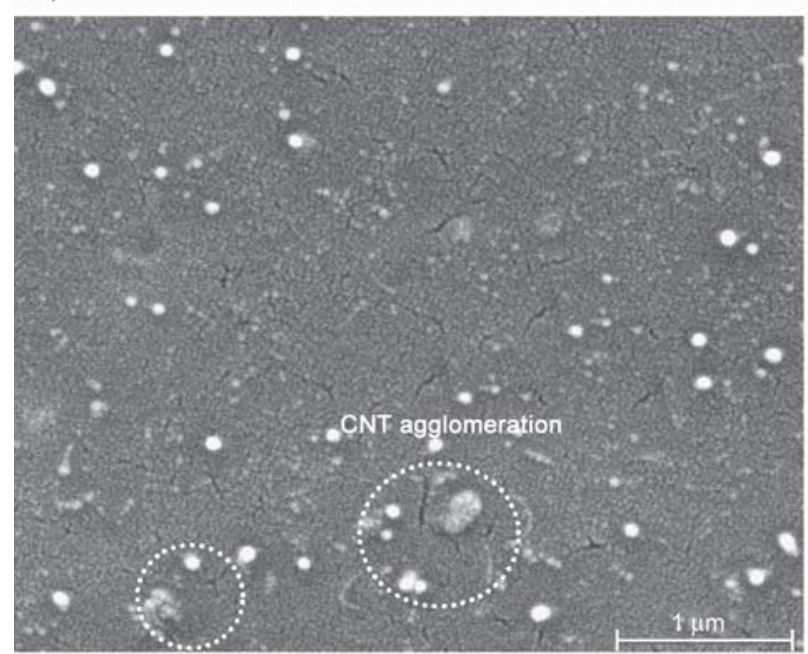

c) the NR/CNT composite. However, a finer dispersion of CNT with smaller aggregates is also seen in the NR/CNT-IL composite (Figure 17d). Therefore, the plasticizing effect of IL effectively reduced CNT agglomeration and supported stronger three-dimensional network formation of CNT bundles. This might be attributed to the IL (BMI) reducing the Van der Waals forces between CNT bundles. The CNT particles were eventually covered by the IL molecules (as seen in Figure 11) that hindered the Van der Waals forces. Therefore, it is concluded that the morphological properties corroborate improved dispersion of CNT and formation of three-dimensional CNT networks in NR matrix by hybrid CNT-IL filler, which matches also other observations, of torque difference (Figure 3), storage modulus (Figure 7) and electrical properties (Figure 13).

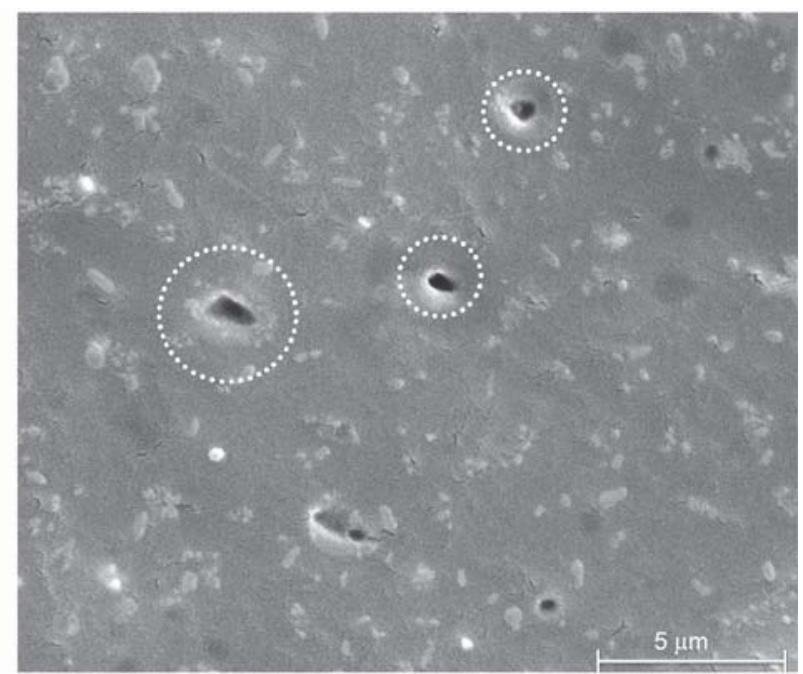

b)

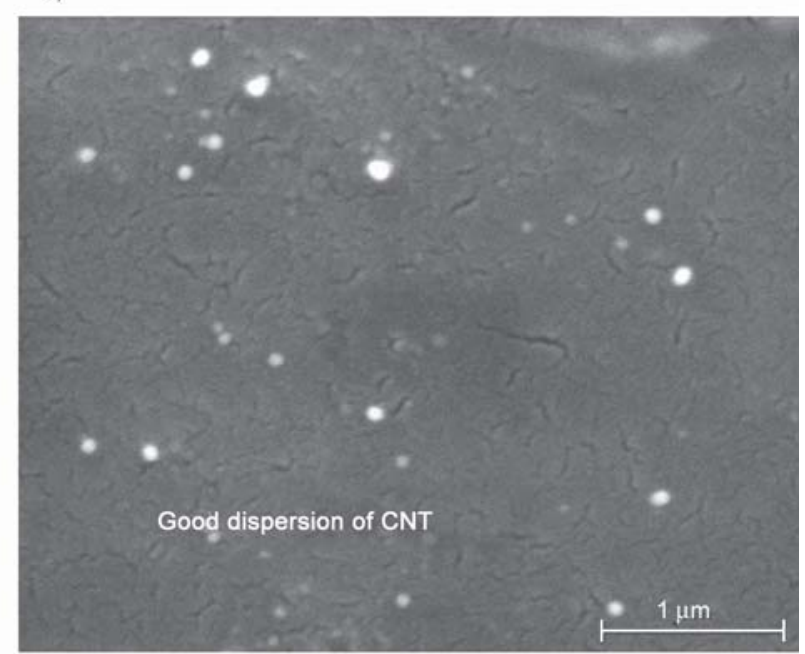

d)

Figure 17. SEM micrographs of NR/IL (focused on the white spots) (a), and NR/IL (focused on the cavitations) (b), NR/CNT (c) and NR/CNT-IL (d) composites. 


\subsection{Mechanical properties}

Figure 18 shows stress-strain curves of gum NR vulcanizate together with NR/CNT, NR/IL and NR/ CNT-IL composites. Also, tensile properties in terms of 100 and $300 \%$ moduli, tensile strength, and elongation at break are summarized in Table 9. It is seen that the addition of CNT, IL and CNT-IL affected the stress-strain behavior of NR vulcanizates. Furthermore, addition of IL (BMI) significantly increased the modulus of NR composite from that of the gum NR vulcanizate, which matches well the initial relaxation moduli (Figure 9 and Table 6). Also, this result agrees with the addition of IL ( $5 \mathrm{phr}$ ) in the ENR matrix increasing the Young's modulus [48]. This might be due to the physical interactions by $\pi$ bonds of NR molecules and imidazolium rings [48]. In addition, lower $100 \%$ but higher $300 \%$ moduli were observed for the NR/IL than for the NR/CNT composite. This means that the NR/IL composites gained rigidity from added IL (BMI) via the physical interactions of NR and IL, as well as from the crystalline IL(BMI) phase in the matrix [48]. However, the hybrid CNT-IL filler gave the highest moduli with synergy of CNT and IL (BMI), along with the interactions among IL, CNT and NR described in Figure 2 (Reaction B).

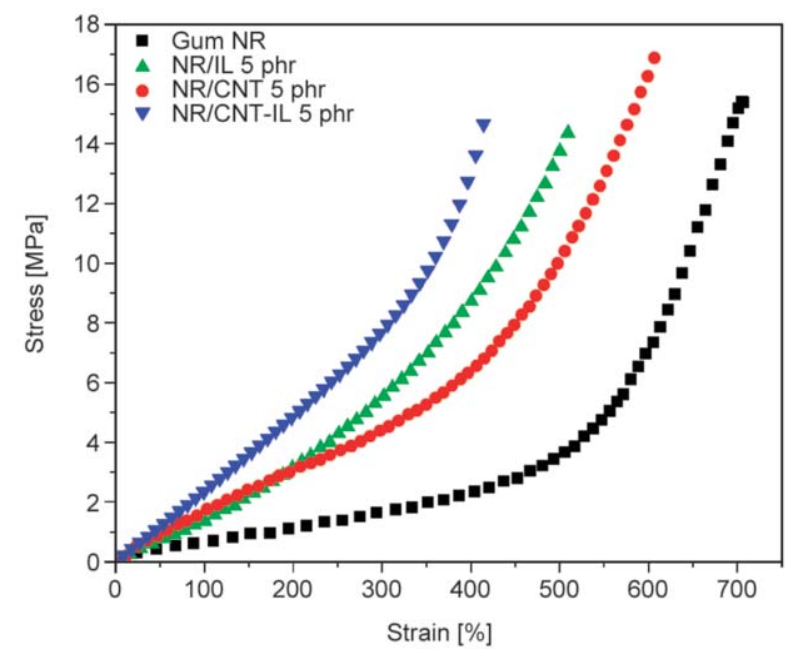

Figure 18. Stress-train curve of the gum NR vulcanizate together with NR/CNT, NR/IL and NR/CNT-IL composites.
This result matches well the initial moduli from the TSSR measurements (Figure 9) and the storage moduli from DMA measurements (Figure 16). In Table 9, lower tensile strength and elongation at break were seen with the addition of IL (BMI) than for the gum NR vulcanizate. Furthermore, higher tensile strength was observed for the NR/CNT composites for the gum NR and NR-IL vulcanizates. Moreover, slightly lower tensile strength and elongation at break were observed for the NR/CNT-IL than for the NR/CNT composites. This might be because the small IL molecules freely dispersed in the NR matrix and acted as defects that initiate failure, similar to that in the ENR/IL composite [48].

Effects of CNT, IL and CNT-IL on strain-induced crystallization of NR composites can be assessed from plots of reduced stress as functions of extension, according to the Mooney-Rivlin Equation (11) [49]:

$\sigma^{*}=\frac{\sigma}{\lambda-\frac{1}{\lambda^{2}}}$

where $\sigma$ and $\lambda$ are the stress and the extension ratio, respectively.

Figure 19 shows Mooney-Rivlin plots for the gum NR vulcanizate together with NR/CNT, NR/IL and NR/CNT-IL composites. According to the James and Guth approach [50], the reduced stress $\left(\sigma^{*}\right)$ indicates the elastic modulus of composites [48] together with degree of strain-induced crystallization in the rubber vulcanizates, which can be estimated from the initial slope with $(1 / \lambda)<0.01$. It is seen that the gum NR vulcanizate showed the highest slope of 0.08 , while the NR composites with IL, CNT and CNT-IL showed lower slopes at $0.02,0.05$ and 0.03 , respectively. Therefore, the addition of CNT or CNT-IL affected significantly the crystallization behavior of NR during extension. This might be attributed to the interactions of CNT with NR by physical crosslinks that hindered orientation of the NR [5]. In the NR/IL composite, the crystalline BMI also restricted NR mobility, consequently reducing strain induced crystallization

Table 9. Mechanical properties in terms of tensile strength, elongation at break, and 100 and $300 \%$ moduli for the gum NR compound together with NR/CNT, NR/IL and NR/CNT-IL composites.

\begin{tabular}{|c|c|c|c|c|}
\hline Sample & $\begin{array}{c}100 \% \text { modulus } \\
{[\mathrm{MPa}]}\end{array}$ & $\begin{array}{c}300 \% \text { modulus } \\
{[\mathrm{MPa}]}\end{array}$ & $\begin{array}{c}\text { Tensile strength } \\
\text { [MPa] }\end{array}$ & $\begin{array}{c}\text { Elongation at break } \\
{[\%]}\end{array}$ \\
\hline Gum NR & $0.73 \pm 0.20$ & $1.63 \pm 1.85$ & $15.59 \pm 2.78$ & $709.30 \pm 10.57$ \\
\hline NR/IL 5 phr & $1.35 \pm 0.45$ & $5.47 \pm 1.82$ & $14.89 \pm 1.92$ & $514.64 \pm 52.28$ \\
\hline NR/CNT 5 phr & $1.67 \pm 0.06$ & $4.47 \pm 0.15$ & $16.50 \pm 0.36$ & $606.93 \pm 29.31$ \\
\hline NR/CNT-IL 5 phr & $2.36 \pm 0.69$ & $7.73 \pm 1.88$ & $15.13 \pm 2.31$ & $418.02 \pm 53.87$ \\
\hline
\end{tabular}




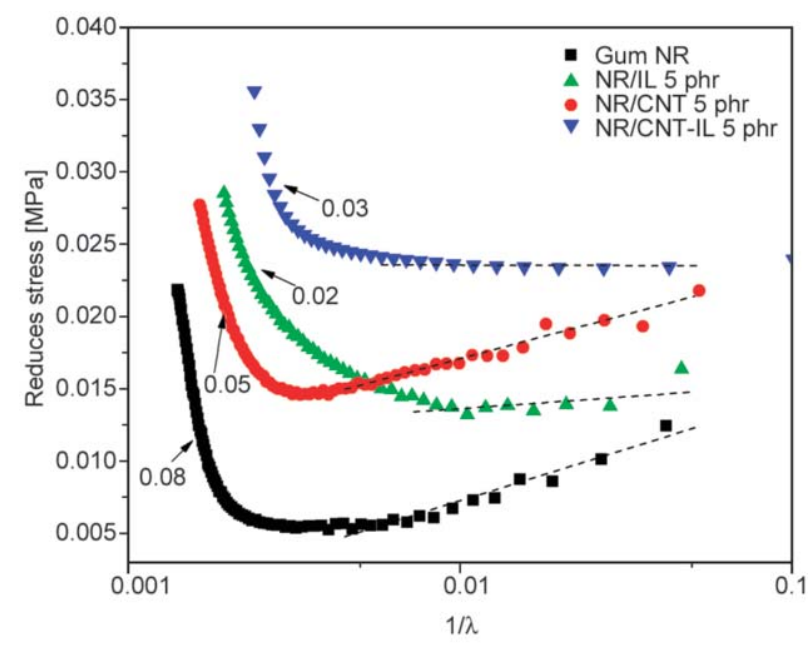

Figure 19. Mooney-Rivlin plot of gum NR vulcanizate together with NR/CNT, NR/IL and NR/CNT-IL composites.

of the NR. Thus, incorporation of CNT-IL gave a slope (0.03) between those of the NR/CNT (0.05) and the NR/IL (0.02) composites. It is anticipated that some of the BMI reacted with CNT by physical adsorption. This could decrease the amount of crystalline BMI dispersed in the NR matrix. Therefore, adding IL (BMI) in the NR decreased torque difference (Figure 3) and storage moduli (Figure 7), but increased the initial moduli (Figure 9) and 100\% moduli (Figure 18). In summary the combination CNT-IL had synergistic effects by enabling the CNT to form an infinite three-dimensional network in the NR matrix. This enhanced the dynamic properties (Figures 7 and 16), mechanical properties (Figures 18 and 19) and electrical properties (Figure 13) of NR composites from those of the gum NR vulcanizate.

\section{Conclusions}

The NR/CNT, NR/IL and NR/CNT-IL composites were prepared by latex mixing method. ATR-FTIR was then used to confirm the presence of IL and to assess the interactions of IL with CNT and NR. It was found that the $\mathrm{C}=\mathrm{C}$ bonds in NR decreased and even disappeared after addition of CNT in NR matrix. This might indicate chemical interactions of NR and CNT. Furthermore, the dipole-dipole and $\pi-\pi$ interactions of CNT and IL (BMI) were confirmed. It was also found that IL significantly influenced the vulcanization reaction kinetics in NR compounds. That is, the BMI might act as a cure retardant increasing the scorch time to favor safe processing of the NR compound. Also, the plasticizing effect of BMI contributed to finer CNT dispersion in the NR matrix and three-dimensional filler network formation, and hence reduced the activation energy of vulcanization. However, conversion by vulcanization in the NR/IL compound decreased owing to reactions of imidazolium rings in IL (BMI) and mercaptobenzthiazole rings in MBT. This consumed some accelerator that initiates and propagates the vulcanization. In addition, the highest Payne effect was found in NR/CNT-IL composite, attributed to the three-dimensional CNT network formation in the NR matrix. Also, $T_{\mathrm{g}}$ increased with the addition of CNT-IL indicating mobility restrictions of NR. Furthermore, the NR/CNT-IL composites showed improved storage modulus, initial stress $\left(\sigma_{0}\right)$, and 100 and $300 \%$ moduli of the composites from those of the gum NR vulcanizate. Incorporation of CNT-IL in NR matrix also had a synergistic effect on the electrical conductivity, because both CNT and IL (BMI) support electron transport. This effectively enhanced the electrical conductivity of the NR composites, by formation of three-dimensional CNT networks. Therefore, the NR/CNT-IL showed the best electrical conductivity and the least percolation threshold concentration.

\section{Acknowledgements}

This work was supported by Thailand Research Fund through the Royal Golden Jubilee Ph.D. Program (grant no. PHD/0209/2557), PSU NR-IRI (Natural Rubber Innovation Research Institute) Contract no. SIT591146S, and the Thailand Research Fund under the Distinguished Research Professor Grant no. DPG6080001. In addition, Faculty of Science and Industrial Technology, Prince of Songkla University Surat Thani campus and University of Applied Science, Osnabrück, Germany are highly acknowledged for access to facilities and equipment. English language proofing by Assoc. Prof. Dr. Seppo Karrila is also acknowledged.

\section{References}

[1] Tamil Selvan N., Eswaran S. B., Das A., Stöckelhuber K. W., Wießner S., Pötschke P., Nando G. B., Chervanyov A. I., Heinrich G.: Piezoresistive natural rubbermultiwall carbon nanotube nanocomposite for sensor applications. Sensors and Actuators A, 239, 102-113 (2016).

https://doi.org/10.1016/j.sna.2016.01.004

[2] Deng F., Ito M., Noguchi T., Wang L., Ueki H., Niihara K., Kim Y. A., Endo M., Zheng Q-S.: Elucidation of the reinforcing mechanism in carbon nanotube/ rubber nanocomposites. ACS nano, 5, 3858-3866 (2011). https://doi.org/10.1021/nn200201u 
[3] Jose T., Moni G., Salini S., Raju A. J., George J. J., George S. C.: Multifunctional multi-walled carbon nanotube reinforced natural rubber nanocomposites. Industrial Crops and Products, 105, 63-73 (2017).

https://doi.org/10.1016/j.indcrop.2017.04.047

[4] Jin S., Park Y. J., Min H. S.: A three-dimensional simulation of quantum transport in silicon nanowire transistor in the presence of electron-phonon interactions. Journal of Applied Physics, 99, 123719/1-123719/10 (2006). https://doi.org/10.1063/1.2206885

[5] Krainoi A., Kummerlöwe C., Nakaramontri Y., Vennemann N., Pichaiyut S., Wisunthorn S., Nakason C.: Influence of critical carbon nanotube loading on mechanical and electrical properties of epoxidized natural rubber nanocomposites. Polymer Testing, 66, 122-136 (2018).

https://doi.org/10.1016/j.polymertesting.2018.01.003

[6] Ma H. M., Gao X-L.: A three-dimensional Monte Carlo model for electrically conductive polymer matrix composites filled with curved fibers. Polymer, 49, 4230 4238 (2008).

https://doi.org/10.1016/j.polymer.2008.07.034

[7] Subramaniam K., Das A., Simon F., Heinrich G.: Networking of ionic liquid modified CNTs in SSBR. European Polymer Journal, 49, 345-352 (2013). https://doi.org/10.1016/j.eurpolymj.2012.10.023

[8] Nakaramontri Y., Nakason C., Kummerlöwe C., Vennemann N.: Influence of modified natural rubber on properties of natural rubber-carbon nanotube composites. Rubber Chemistry and Technology, 88, 199-218 (2015). https://doi.org/10.5254/rct.14.85949

[9] Subramaniam K., Das A., Steinhauser D., Klüppel M., Heinrich G.: Effect of ionic liquid on dielectric, mechanical and dynamic mechanical properties of multiwalled carbon nanotubes/polychloroprene rubber composites. European Polymer Journal, 47, 2234-2243 (2011). https://doi.org/10.1016/j.eurpolymj.2011.09.021

[10] Ahmadian Hoseini A. H., Arjmand M., Sundararaj U., Trifkovic M.: Significance of interfacial interaction and agglomerates on electrical properties of polymer-carbon nanotube nanocomposites. Materials and Design, 125, 126-134 (2017).

https://doi.org/10.1016/j.matdes.2017.04.004

[11] Umapathi R., Venkatesu P.: Thermo-responsive triblock copolymer phase transition behaviour in imidazoliumbased ionic liquids: Role of the effect of alkyl chain length of cations. Journal of Colloid and Interface Science, 485, 183-191 (2017).

https://doi.org/10.1016/j.jcis.2016.09.034

[12] Fukushima T., Kosaka A., Yamamoto Y., Aimiya T., Notazawa S., Takigawa T., Inabe T., Aida T.: Dramatic effect of dispersed carbon nanotubes on the mechanical and electroconductive properties of polymers derived from ionic liquids. Small, 2, 554-600 (2006). https://doi.org/10.1002/smll.200500404
[13] Das A., Stöckelhuber K. W., Jurk R., Fritzsche J., Klüppel M., Heinrich G.: Coupling activity of ionic liquids between diene elastomers and multi-walled carbon nanotubes. Carbon, 47, 3313-3321 (2009).

https://doi.org/10.1016/j.carbon.2009.07.052

[14] Marwanta E., Mizumo T., Nakamura N., Ohno H.: Improved ionic conductivity of nitrile rubber/ionic liquid composites. Polymer, 46, 3795-3800 (2005).

https://doi.org/10.1016/j.polymer.2005.02.113

[15] Marzec A., Laskowska A., Boiteux G., Zaborski M., Gain O., Serghei A.: The impact of imidazolium ionic liquids on the properties of nitrile rubber composites. European Polymer Journal, 53, 139-146 (2014). https://doi.org/10.1016/j.eurpolymj.2014.01.035

[16] Laskowska A., Marzec A., Boiteux G., Zaborski M., Gain O., Serghei A., Maniukiewicz W.: Improving the ionic conductivity of carboxylated nitrile rubber/LDH composites by adding imidazolium bis(trifluoromethylsulfonyl)imide ionic liquids. Macromolecular Symposia, 342, 35-45 (2014).

https://doi.org/10.1002/masy.201300232

[17] George N., Bipinbal P. K., Bhadran B., Mathiazhagan V., Joseph R.: Segregated network formation of multiwalled carbon nanotubes in natural rubber through surfactant assisted latex compounding: A novel technique for multifunctional properties. Polymer, 112, 264-277 (2017). https://doi.org/10.1016/j.polymer.2017.01.082

[18] Nakaramontri Y., Nakason C., Kummerlöwe C., Vennemann N.: Enhancement of electrical conductivity and filler dispersion of carbon nanotube filled natural rubber composites by latex mixing and in situ silanization. Rubber Chemistry and Technology, 89, 272-291 (2016). https://doi.org/10.5254/rct.15.84848

[19] Vennemann N., Wu M.: Thermoelastic properties and relaxation behavior of S-SBR/silica vulcanizates. Rubber World, 246, 18-23 (2012)

[20] Du F., Fischer J., Winey K.: Coagulation method for preparing single-walled carbon nanotube/poly(methyl methacrylate) composites and their modulus, electrical conductivity, and thermal stability. Journal of Polymer Science Part B, 41, 3333-3338 (2003).

https://doi.org/10.1002/polb.10701

[21] Safadi B., Andrews R., Glurke E. A.: Multiwalled carbon nanotube polymer composites: Synthesis and characterization of thin films. Journal of Applied Polymer Science, 84, 2660-2669 (2002).

https://doi.org/10.1002/app.10436

[22] Coates J.: Interpretation of infrared spectra, A practical approach. in 'Encyclopedia of analytical chemistry' (eds.: Meyers R. A.) Wiley, New York, 6-15 (2006). https://doi.org/10.1002/9780470027318.a5606

[23] Laskowska A., Marzec A., Boiteux G., Zaborski M., Gain O., Serghei A.: Investigations of nitrile rubber composites containing imidazolium ionic liquids. Macromolecular Symposia, 341, 18-25 (2014). https://doi.org/10.1002/masy.201300150 
[24] Sun H., Song X., Xu M., Zhang Y., Que W., Yang S.: Functionalization of carbon nanotubes via Birch reduction chemistry for selective loading of $\mathrm{CuO}$ nanosheets. New Journal of Chemistry, 39, 4278-4283 (2015). https://doi.org/10.1039/C5NJ00283D

[25] Bevilacqua E. M., English E. S.: The scission step in hevea oxidation. Journal of Polymer Science, 49, 495505 (1961).

https://doi.org/10.1002/pol.1961.1204915229

[26] Zheng W., Jia Z., Zhang Z., Yang W., Zhang L., Wu S.: Improvements of lanthanum complex on the thermaloxidative stability of natural rubber. Journal of Materials Science, 51, 9043-9056 (2016).

https://doi.org/10.1007/s10853-016-0157-4

[27] Kiefer J., Fries J., Leipertz A.: Experimental vibrational study of imidazolium-based ionic liquids: Raman and infrared spectra of 1-ethyl-3-methylimidazolium bis(trifluoromethylsulfonyl)imide and 1-ethyl-3-methylimidazolium ethylsulfate. Applied Spectroscopy, 61, 1307 1311 (2007).

https://doi.org/10.1366/000370207783292000

[28] Subramaniam K., Das A., Stöckelhuber K. W., Heinrich G.: Elastomer composites based on carbon nanotubes and ionic liquid. Rubber Chemistry and Technology, 86, 367-400 (2013)

https://doi.org/10.5254/rct.13.86984

[29] Wang J., Chu H., Yan Li.: Why single-walled carbon nanotubes can be dispersed in imidazolium-based ionic liquids. ACS Nano, 2, 2540-2546 (2008).

https://doi.org/10.1021/nn800510g

[30] Wang Q.: Atomic transportation via carbon nanotubes. Nano Letters, 9, 245-249 (2009).

https://doi.org/10.1021/nl802829z

[31] Marzec A., Laskowska A., Boiteux G., Zaborski M., Gain O., Serghei A.: Properties of carboxylated nitrile rubber/hydrotalcite composites containing imidazolium ionic liquids. Macromolecular Symposia, 341, 7-17 (2014). https://doi.org/10.1002/masy.201300149

[32] López-Manchado M. A., Arroyo M., Herrero B., Biagiotti J.: Vulcanization kinetics of natural rubber-organoclay nanocomposites. Journal of Applied Polymer Science, 89, 1-15 (2003).

https://doi.org/10.1002/app.12082

[33] Perez L. D., Zuluaga M. A., Kyu T., Mark J. E., Lopez B. L.: Preparation, characterization, and physical properties of multiwall carbon nanotube/elastomer composites. Polymer Engineering and Science, 49, 866-874 (2009).

https://doi.org/10.1002/pen.21247

[34] Salaeh S., Boiteux G., Cassagnau P., Nakason C.: Flexible $0-3$ ceramic-polymer composites of barium titanate and epoxidized natural rubber. International Journal of Applied Ceramic Technology, 12, 106-115 (2015). https://doi.org/10.1111/ijac.12129

[35] Jürgen E. K.: Collected application thermal analysis. Schwerzenbach, Switzerland (2002).
[36] Wei C., Srivastava C., Cho K.: Thermal expansion and diffusion coefficients of carbon nanotube-polymer composites. Nano Letters, 2, 647-650 (2002).

https://doi.org/10.1021/n1025554

[37] Payne A. R., Whittaker R. E.: Low strain dynamic properties of filled rubber. Rubber Chemistry and Technology, 44, 440-478 (1971).

https://doi.org/10.5254/1.3547375

[38] Pongdong W., Kummerlöwe C., Vennemann N., Thitithammawong A., Nakason C.: A comparative investigation of rice husk ash and siliceous earth as reinforcing fillers in dynamically cured blends of epoxidized natural rubber (ENR) and thermoplastic polyurethane (TPU). Journal of Polymers and the Environment, 26, 1145-1159 (2018). https://doi.org/10.1007/s10924-017-1022-5

[39] Gatos K. G., Sawanis N. S., Apostolov A. A., Thomann R., Karger-Kocsis J.: Nanocomposite formation in hydrogenated nitrile rubber (HNBR)/organo-montmorillonite as a function of the intercalant type. Macromolecular Materials and Engineering, 289, 1079-1086 (2004).

https://doi.org/10.1002/mame.200400214

[40] Le H. H., Ilisch S., Radusch H. J.: Characterization of the effect of the filler dispersion on the stress relaxation behavior of carbon black filled rubber composites. Polymer, 50, 2294-2303 (2009). https://doi.org/10.1016/j.polymer.2009.02.051

[41] Barbe A., Bökamp K., Kummerlöwe C., Sollmann H., Vennemann N.: Investigation of modified SEBS-based thermoplastic elastomers by temperature scanning stress relaxation measurements. Polymer Engineering and Science, 45, 1498-1507 (2005).

https://doi.org/10.1002/pen.20427

[42] Ferry J. D.: Viscoelastic properties of polymers. Wiley, New York (1980).

[43] Pham G. T.: Characterization and modeling of piezoresistive properties of carbon nanotube-based conductive polymer composites. PhD thesis, Florida State University, Tallahassee (2008).

[44] Ma P-C., Siddiqui N. A., Marom G., Kim J-K.: Dispersion and functionalization of carbon nanotubes for polymer-based nanocomposites: A review. Composites Part A: Applied Science and Manufacturing, 41, 1345-1367 (2010). https://doi.org/10.1016/j.compositesa.2010.07.003

[45] Li L., Yao X., Li H., Liu Z., Ma W., Liang X.: Thermal stability of oxygen-containing functional groups on activated carbon surfaces in a thermal oxidative environment. Journal of Chemical Engineering of Japan, 47, 21-27 (2014). https://doi.org/10.1252/jcej.13we193

[46] Bai J., Goodridge R. D., Hague R. J. M., Song M., Okamoto M.: Influence of carbon nanotubes on the rheology and dynamic mechanical properties of polyamide12 for laser sintering. Polymer Testing, 36, 95-100 (2014).

https://doi.org/10.1016/j.polymertesting.2014.03.012 
[47] Nakason C., Panklieng Y., Kaesaman A.: Rheological and thermal properties of thermoplastic natural rubbers based on poly(methyl methacrylate)/epoxidized-natural-rubber blends. Journal of Applied Polymer Science, 92, 3561-3572 (2004).

https://doi.org/10.1002/app.20384

[48] Matchawet S., Kaesaman A., Vennemann N., Kumerlöwe C., Nakason C.: Effects of imidazolium ionic liquid on cure characteristics, electrical conductivity and other related properties of epoxidized natural rubber vulcanizates. European Polymer Journal, 87, 344-359 (2017).

https://doi.org/10.1016/j.eurpolymj.2016.12.037
[49] Bhattacharyya S., Sinturel C., Bahloul O., Saboungi M-L., Thomas S., Salvetat J-P.: Improving reinforcement of natural rubber by networking of activated carbon nanotubes. Carbon, 46, 1037-1045 (2008). https://doi.org/10.1016/j.carbon.2008.03.011

[50] James H. M., Guth E.: Theory of the elastic properties of rubber. The Journal of Chemical Physics, 15, 455481 (1943).

https://doi.org/10.1063/1.1723785 